Full length article

\title{
Simvastatin and nanofibrous poly(L-lactic acid) scaffolds to promote the odontogenic potential of dental pulp cells in an inflammatory environment
}

\author{
Diana G. Soares ${ }^{\mathrm{a}, \mathrm{b}}$, Zhanpeng Zhang ${ }^{\mathrm{c}}$, Fatma Mohamed ${ }^{\mathrm{a}}$, Thomas W. Eyster ${ }^{\mathrm{a}}$, Carlos A. de Souza Costa ${ }^{\mathrm{b}}$, \\ Peter X. Ma ${ }^{\mathrm{a}, \mathrm{c}, \mathrm{d}, \mathrm{e}, *}$
}

a Department of Biologic and Materials Science, University of Michigan, Ann Arbor, MI 48109, USA

${ }^{\mathrm{b}}$ Department of Physiology and Pathology, Araraquara School of Dentistry, Univ. Estadual Paulista, Araraquara, São Paulo, Brazil

${ }^{\mathrm{C}}$ Macromolecular Science and Engineering Center, University of Michigan, Ann Arbor, MI 48109, USA

${ }^{\mathrm{d}}$ Department of Biomedical Engineering, University of Michigan, Ann Arbor, MI 48109, USA

${ }^{\mathrm{e}}$ Department of Materials Science and Engineering, University of Michigan, Ann Arbor, MI 48109, USA

\section{A R T I C L E I N F O}

\section{Article history:}

Received 16 September 2017

Received in revised form 15 December 2017

Accepted 22 December 2017

Available online 30 December 2017

\section{Keywords:}

Dental pulp cells (DPCs)

Nanofibrous poly(L-lactic acid) scaffold

Simvastatin

Inflammation

\begin{abstract}
A B S T R A C T
In this study, we investigated the anti-inflammatory, odontogenic and pro-angiogenic effects of integrating simvastatin and nanofibrous poly(L-lactic acid) (NF-PLLA) scaffolds on dental pulp cells (DPCs). Highly porous NF-PLLA scaffolds that mimic the nanofibrous architecture of extracellular matrix were first fabricated, then seeded with human DPCs and cultured with $0.1 \mu \mathrm{M}$ simvastatin and/or $10 \mu \mathrm{g} / \mathrm{mL}$ proinflammatory stimulator lipopolysaccharide (LPS). The gene expression of pro-inflammatory mediators (TNF- $\alpha$, IL-1 $\beta$ and MMP-9 mRNA) and odontoblastic markers (ALP activity, calcium content, DSPP, DMP-1 and BMP-2 mRNA) were quantified after long-term culture in vitro. In addition, we evaluated the scaffold's pro-angiogenic potential after $24 \mathrm{~h}$ of in vitro co-culture with endothelial cells. Finally, we assessed the combined effects of simvastatin and NF-PLLA scaffolds in vivo using a subcutaneous implantation mouse model. The in vitro studies demonstrated that, compared with the DPC/NF-PLLA scaffold constructs cultured only with pro-inflammatory stimulator LPS, adding simvastatin significantly repress the expression of pro-inflammatory mediators. Treating LPS+ DPC/NF-PLLA constructs with simvastatin also reverted the negative effects of LPS on expression of odontoblastic markers in vitro and in vivo. Western blot analysis demonstrated that these effects were related to a reduction in NFkBp65 phosphorylation and up-regulation of PPAR $\gamma$ expression, as well as to increased phosphorylation of pERK1/2 and pSmad1, mediated by simvastatin on LPS-stimulated DPCs. The DPC/NF-PLLA constructs treated with LPS/simvastatin also led to an increase in vessel-like structures, correlated with increased VEGF expression in both DPSCs and endothelial cells. Therefore, the combination of low dosage simvastatin and NF-PLLA scaffolds appears to be a promising strategy for dentin regeneration with inflamed dental pulp tissue, by minimizing the inflammatory reaction and increasing the regenerative potential of resident stem cells.
\end{abstract}

\section{Statement of Significance}

The regeneration potential of stem cells is dependent on their microenvironment. In this study, we investigated the effect of the microenvironment of dental pulp stem cells (DPSCs), including 3D structure of a macroporous and nanofibrous scaffold, the inflammatory stimulus lipopolysaccharide (LPS) and a biological molecule simvastatin, on their regenerative potential of mineralized dentin tissue. The results demonstrated that LPS upregulated inflammatory mediators and suppressed the odontogenic potential of DPSCs. Known as a lipid-lowing agent, simvastatin was excitingly found to repress the expression of pro-inflammatory mediators, up-regulate odontoblastic markers, and exert a pro-angiogenic effect on

\footnotetext{
* Corresponding author at: Department of Biologic \& Materials Sciences, University of Michigan, Ann Arbor, MI 48109, USA.

E-mail address: mapx@umich.edu (P.X. Ma).
} 
endothelial cells, resulting in enhanced vascularization and mineralized dentin tissue regeneration in a biomimetic 3D tissue engineering scaffold. This novel finding is significant for the fields of stem cells, inflammation and dental tissue regeneration.

(c) 2017 Acta Materialia Inc. Published by Elsevier Ltd. All rights reserved.

\section{Introduction}

Dentin tissue engineering relies on the development of advanced scaffolds that facilitate the regeneration of the remaining vital pulp tissue, effectively harnessing the innate capacity of dental pulp for self-repair [1-3]. Inflammation resulting from infected dental caries commonly causes a disruption to the dynamic equilibrium of the dental pulp [4,5]. Sustained pulpal inflammation not only damages the pulp tissue itself, but also prevents the repair response by down-regulating the recruitment and differentiation of mesenchymal progenitor cells [6]. Therefore, an ideal scaffold for dentin tissue engineering should not only induce odontoblastic differentiation of mesenchymal stem cells, but also play a role in mitigating the inflammatory reaction.

A nanofibrous poly(L-lactic acid) (NF-PLLA) scaffold developed by our group has generated promising results in mineralized tissue regeneration $[1,2,7-11]$. The highly interconnected spherical macroporous structure promotes the migration of mesenchymal stem cells within the material, where they can adhere, spread and proliferate [11-14]. This unique material features a nanofibrous pore wall architecture that structurally simulates type I collagen fibers and directly modifies cell behaviors, including adhesion, proliferation and differentiation $[15,16]$. It has recently been shown that NF-PLLA scaffolds induce dental pulp stem cells (DPSCs) to differentiate into highly secretive odontoblast-like cells in vitro $[1,17]$. Moreover, the cells maintained their differentiated phenotype and formed hard tissue after 8 weeks of subcutaneous implantation in nude mice. However, the regenerative potential of dental pulp cells/NF-PLLA constructs has not been investigated in an intense inflammatory environment.

Simvastatin, a small molecule drug used to treat hyperlipidemia, has emerged as a co-adjuvant for dentin regeneration due to its pleiotropic effects, including its ability to decrease inflammation, improve endothelial function and enhance mineralized tissue deposition by osteoblasts/odontoblast precursors [18,19]. However, the positive effects of simvastatin seem to be concentration dependent, since at high concentrations (10-50 $\mu \mathrm{M})$, cell death, inhibition of mesenchymal stem cells differentiation and angiogenesis are observed [20-23]. Some investigators have demonstrated that at low concentrations $(0.01-1 \mu \mathrm{M})$, this molecule is capable of inducing mineralized tissue deposition in vitro and in vivo, via a mevalonate independent pathway [5,22-28]. Others have demonstrated that systemic administration of this drug plays a positive role in treating inflamed periodontal tissue, leading to increased bone deposition [29,30]. However, negative effects on bone regeneration mediated by simvastatin-loaded scaffolds have been reported in the literature, which seems to be associated with high dosages [31]. Nevertheless, the anti-inflammatory potential of simvastatin has been widely demonstrated at high concentrations, such as $10-50 \mu \mathrm{M}$, and the mechanism underlying simvastatinmediated suppression of pro-inflammatory cytokine and metalloproteinases has been associated with blocking of mevalonate and NF- $\kappa B$ pathways [32-34]. However, there is evidence that even at low-concentrations, simvastatin is capable to modulate NF- $\kappa \mathrm{B}$ [35]. In this study, we integrated low-dosage simvastatin and NFPLLA scaffolds to test our hypothesis of this combination to enhance regenerative potential of dental pulp cells in an inflammatory environment.

\section{Material and methods}

\subsection{Establishment of dental pulp cells (DPCS)}

Fresh pulp tissue from sound human third molars ( $<24$ years old; $n=4)$ was collected and subjected to enzymatic digestion in collagenase type 1 ( $3 \mathrm{mg} / \mathrm{mL}$; Sigma-Aldrich, St. Louis, MO, USA). The resulting cells were re-suspended in complete $\alpha$-MEM (Minimum Essential Medium Eagle Alpha, supplemented with 10\% fetal bovine serum FBS, L-glutamine and $1 \%$ penicillin-streptomycin; GIBCO, Thermo Fisher Scientific, Carlsbad, CA, USA), and incubated for $3 \mathrm{~h}$ in culture plates at $37{ }^{\circ} \mathrm{C}$ and $5 \% \mathrm{CO}_{2}$. The adherent cells were then sub-cultured in complete $\alpha$-MEM, and cells at passage 3 were assayed for the stem cell markers STRO-1, OCT3/4 and CD-146 via immunofluorescence staining [36]. Briefly, cells were seeded on 24-well plates (Corning Inc., Corning, NY, USA) at $80 \%$ confluency. They were then fixed in $4 \%$ paraformaldehyde (PFA; Sigma Aldrich), permeabilized in $0.1 \%$ Triton X (Sigma Aldrich), blocked in $2 \%$ bovine serum albumin (BSA, Santa Cruz Biotechnology, Santa Cruz, CA, USA) and incubated with primary antibodies (Santa Cruz; 1:50 2\% BSA) overnight at $4{ }^{\circ} \mathrm{C}$. Then, the cells were washed and incubated for $1 \mathrm{~h}$ at room temperature with phycoerythrin (PE)-conjugated secondary antibody (Santa Cruz; 1:100 2\% BSA) and covered with DAPI (Santa Cruz) for nuclear staining. The percentage of positive staining for each stem cell marker was calculated by means of Image J, in 4 pictures per sample $(n=3)$ obtained on fluorescence microscopy (Fig. 1). Cells at passage \# 3 to 6 were used in this study.

\subsection{Determination lipopolysaccharide (LPS) concentration}

The effect of LPS (Escherichia coli; Sigma-Aldrich) on the viability and differentiation of DPCs was first evaluated. Cells were seeded on 96 well plates (Corning) (5.000 cells/well) in complete $\alpha$-MEM and incubated for $3 \mathrm{~h}$. Then, the medium was replaced with osteogenic medium (containing $50 \mu \mathrm{g} / \mathrm{mL}$ ascorbic acid, 5 $\mathrm{mM} \beta$-glycerophosphate, and $10 \mathrm{nM}$ dexamethasone; SigmaAldrich) with 0,1 or $10 \mu \mathrm{g} / \mathrm{mL}$ LPS. Cell viability $(\mathrm{n}=4)$ was assessed after 1, 3 and 7 days with CellTiter $96{ }^{\circledR}$ Aqueous One Solution (Promega, Madison, WI, USA), according to the manufacturer's instructions. The negative control group $(0 \mu \mathrm{g} / \mathrm{mL}$ LPS $)$ at day 1 was defined as having a cell viability of $100 \%$, and the percentage of cell viability for all groups at the different time-points was calculated based on this parameter. The calcium deposition $(n=4)$ was evaluated after 28 days in culture. The cells were incubated in $1 \mathrm{~N}$ hydrochloric acid $(\mathrm{HCl})$ at $4{ }^{\circ} \mathrm{C}$ overnight, and the quantification of total calcium content was performed using the ocresolphthaleincomplexone method (Calcium LiquiColor, Stambio Laboratory, Boerne, TX, USA). The values of calcium were calculated by a standard curve and then converted to a percentage based on the negative control group (100\% of calcium deposition).

\subsection{Evaluation of the experimental design}

To evaluate the capability of simvastatin (Sigma-Aldrich) for countering inflammation, we used a protocol in which cells were pre-treated with LPS for 7 days to simulate a pre-existing inflammatory condition; then, the drug was added and the cells were cul- 


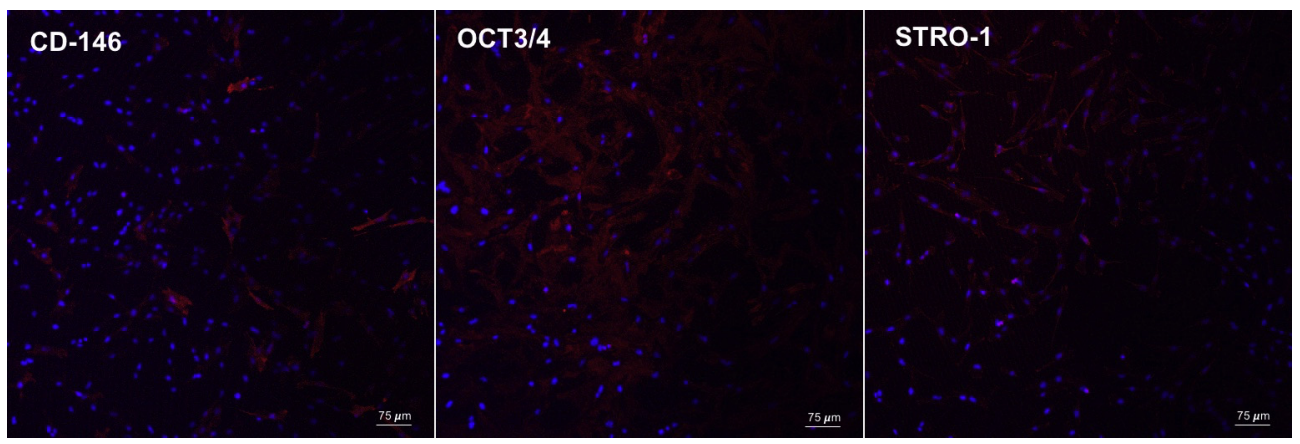

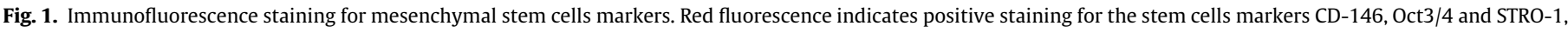
and blue fluorescence indicates the nucleus.

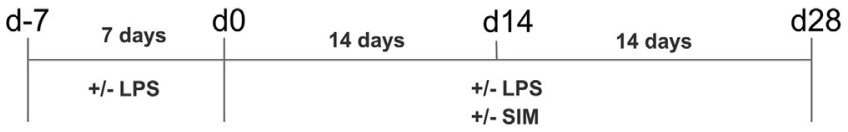

Fig. 2. Experimental design. The cells were seeded at d-7 and cultivated in complete $\alpha$-MEM supplemented with or without $10 \mu \mathrm{g} / \mathrm{mL}$ LPS for 7 days (d-7 to d0). Then, the cells were cultivated in osteogenic medium supplemented with 10 $\mu \mathrm{g} / \mathrm{mL}$ LPS and/or $0.1 \mu \mathrm{M}$ simvastatin for additional 14 days (d0 to d14) or 28 days (d0 to d28).

Table 1

Experimental groups established according to the pre-treatment time with LPS and post-treatment time with LPS and/or simvastatin (SIM).

\begin{tabular}{llll}
\hline Group & Pre-treatment in LPS & \multicolumn{2}{c}{ Post-treatment } \\
\cline { 3 - 4 } & & SIM & LPS \\
\hline SIM-/LPS- & - & - & - \\
SIM+/LPS- & - & + & - \\
SIM+/LPS+ & + & + & + \\
SIM-/LPS+ & + & - & + \\
\hline
\end{tabular}

tivated for up to 28 days (Fig. 2 and Table 1). A bioactive concentration of simvastatin capable of stimulating mineralized tissue deposition on DPCs was chosen for this assay based on literature $[22,23,37]$. The cells were seeded on cell culture plates at $80 \%$ confluency. After three hours, the culture medium was replaced with complete $\alpha$-MEM with or without $10 \mu \mathrm{g} / \mathrm{mL}$ LPS, and the cells were incubated for 7 days at $37^{\circ} \mathrm{C}$ and $5 \% \mathrm{CO}_{2}$ (the culture medium supplemented with LPS was changed every $48 \mathrm{~h}$ ). Following the pretreatment time with LPS, cells were cultivated in osteogenic medium with or without LPS and with or without simvastatin (Fig. 2). The gene expression of TNF- $\alpha(n=4)$ was evaluated after the 7-day pre-treatment time (d0) and after 14 days in the presence of the drug (d14). At each time-point, prior to RNA isolation, the cells were incubated with the culture medium supplemented with or without these molecules for $3 \mathrm{~h}$, since this period represents the peak of pro-inflammatory cytokine expression following LPS exposure in DPCs [38]. Total RNA was isolated with Trizol reagent (Applied Biosystems, Foster City, CA, USA) and $1 \mu \mathrm{g}$ was reverse transcribed into cDNA with TaqMan reverse transcription reagents (Applied Biosystems). Real-time PCR quantitation of TNF- $\alpha$ was performed in a 7500 Real-Time PCR System (Applied Biosystems) with the TaqMan assay (Hs01113624_g1) and reagents (Applied Biosystems). The endogenous gene GAPDH (Hs99999905_m1) was used to normalize the CT values, and data was calculated by using $2^{\Delta \Delta C T}$ method. Alkaline phosphatase (ALP) activity $(n=4)$ (SensoLyte ${ }^{\mathrm{TM}}$ pNpp Alkaline Phosphatase Assay Kit, AnaSpec, CA, USA) and calcium content $(n=4)$ (Calcium LiquiColor) were evaluated at $\mathrm{d} 14$ and $\mathrm{d} 28$, respectively, by following the manufacturer's instructions. Data was converted into percentages based on SIM-/ LPS- group (negative control $=100 \%$ ).

\subsection{Western blot analysis}

The DPSCs were seeded on 6 -well plates $\left(3 \times 10^{5}\right.$ cells $)$ in complete $\alpha$-MEM and incubated for $24 \mathrm{~h}(\mathrm{n}=3)$. Thereafter, the cells were exposed to LPS for $3 \mathrm{~h}$, followed by treatment with simvastatin and/or LPS for $30 \mathrm{~min}$. The same experimental groups described in Table 1 were established. After the experimental procedure, total protein was extracted with the EpiQuik Whole Cell Extraction Kit (Epigentek, Farmingdale, NY, USA) supplemented with PhosStop (1:10) (Sigma-Aldrich). A total of $20 \mu \mathrm{g}$ protein was run through $12 \%$ or $4-20 \%$ Immun-Blot SDS-polyacrylamide gel electrophoresis (Bio-Rad, Hercules, CA, USA) and transferred to a PVDF membrane (Bio-Rad). The blots were washed with $1 \mathrm{x}$ TBS (Bio-Rad) and with 0.05\% Tween 20 (Sigma-Aldrich), blocked in $3 \%$ BSA (Santa Cruz) and incubated overnight at $4{ }^{\circ} \mathrm{C}$ with primary antibodies for pERK1/2, ERK 1/2, pSmad1, Smad1, Smad2/3, pSmad2/3, pNFkBp65 and PPAR $\gamma$ (1:200; Cell Signaling, Danvers, MA, USA). $\beta$-Actin (1:5000; Cell Signaling) was used as endogenous control. Next, the blots were washed in TBST and incubated for $1 \mathrm{~h}$ with horseradish peroxidase-conjugated secondary antibodies (1:5000; Santa Cruz) followed by treatment with chemiluminescence reagent (SuperSignal West Dura, Pierce). The intensity of protein bands was analyzed with ImageJ software (National Institute of Health). The Western blot assay was performed three times with different samples.

\subsection{DPSC/NF-PLLA scaffold constructs}

In order to observe the combined effects of simvastatin and nanofibrous scaffolds on the odontogenic potential of LPSstimulated DPSCs, a macroporous nanofibrous poly(L-lactic acid) (NF-PLLA) scaffold was fabricated following a published phaseseparation method [39]. The material was obtained by casting a solution of PLLA in tetrahydrofuran $(10 \% \mathrm{wt} / \mathrm{v})$ into an interconnected sugar sphere template (250-420 $\mu$ m diameter) under mild vacuum. In order to create a nanofibrous surface topography similar to collagen type I, the polymer-sugar composite was phase separated at $-80^{\circ} \mathrm{C}$ overnight. The solvent and sugar spheres were leached out using cyclohexane and water, respectively, followed by freeze-drying. The scaffold macro and micro topographies were assessed by scanning electron microscopy (SEM) analysis (Philips XL30 FEG, Eindhoven, Netherlands). The scaffolds were cut into circular disks (5 mm diameter and $1 \mathrm{~mm}$ thickness) and sterilized in $70 \%$ ethanol for $30 \mathrm{~min}$, while the air bubbles were removed under vacuum. The scaffolds were then placed at the bottom of 48-well plates, washed in PBS (phosphate-buffered saline) three times for 
thirty minutes each, followed by incubation in complete $\alpha$-MEM overnight at $37{ }^{\circ} \mathrm{C}$ and $5 \% \mathrm{CO}_{2}$. A total of $5 \times 10^{5}$ cells were seeded onto each scaffold followed by incubation for $3 \mathrm{~h}$ in $500 \mu \mathrm{L}$ of complete $\alpha$-MEM. The same experimental design and experimental groups as shown in Fig. 2 and Table 1 were established. Briefly, cells were cultured for 7 days in medium with or without LPS $(10 \mu \mathrm{g} / \mathrm{mL})$, followed by further cultivation in osteogenic medium with or without simvastatin $(0.1 \mu \mathrm{M})$ and with or without LPS up to 28 days.

\subsubsection{Cell adhesion, spread and proliferation on NF-PLLA scaffolds}

The adhesion and spreading of the cells on NF-PLLA scaffolds were analyzed by F-actin staining at d-7, d0, d14 and d28 $(n=2)$. At each time-point, the cell/scaffold construct was washed in PBS, fixed in 4\% PFA (15 min), embedded in an O.C.T compound (Tissue-Tek, Sakura Finetek, Torrance, CA, USA) and frozen at $-80^{\circ} \mathrm{C}$. Samples were cut into $5 \mu \mathrm{m}$ sections, and the slides were permeabilized in $0.1 \%$ Triton X (Thermo Fisher Scientific, Waltham, MA, USA) and incubated for 30 min with Alexa Fluor 488 Phalloidin (1:40; Thermo Fisher Scientific, Carlsbad, CA, USA). Mounting medium with DAPI (ProLong, Thermo Fisher Scientific) was used to stain the nuclei, and representative images at each time point were obtained with fluorescence microscopy. The cell proliferation ( $\mathrm{n}=$ 4) was assessed by DNA quantification (DNA quantitation kit, Sigma-Aldrich) at d-7, d0, d14 and d28. Briefly, the scaffolds were disrupted with $1 \mathrm{x}$ DNA assay lysis buffer and supernatant was collected for DNA content determination using a fluorescence assay with Hoechst 33258 dye.

\subsubsection{ALP activity and calcium deposition}

ALP activity $(n=6)$ was determined at d14 by using a SensoLyte $^{\mathrm{TM}}$ Alkaline Phosphatase Assay Kit (AnaSpec). The samples were manually disrupted and incubated with lysis buffer (TrionX-100) for $10 \mathrm{~min}$ at $4^{\circ} \mathrm{C}$. The supernatant was collected by centrifugation $\left(10,000 \mathrm{~g}\right.$ at $4{ }^{\circ} \mathrm{C}$ for $\left.15 \mathrm{~min}\right)$, and ALP activity was measured per the manufacturer's instructions. Total protein quantification was performed with a micro BCA kit (Thermo Fisher ScientificThermo Fisher Scientific, San Francisco, CA, USA) and the data for ALP activity was obtained after normalization with the total protein amount. The calcium content $(n=6)$ of cell-scaffold constructs was determined at d28 using the calcium assay kit (Calcium LiquiColor, StamBio), after disruption and incubation of samples overnight at $4{ }^{\circ} \mathrm{C}$ with $1 \mathrm{~N} \mathrm{HCl}$. Von Kossa staining was performed on frozen slides $(\mathrm{n}=2)$ by using a standard kit (American MasterTech, Lodi, CA, USA). Quantitative data for ALP activity and calcium content were described as percentages based on the negative control group (SIM-/LPS-).

\subsubsection{Real-time $P C R$}

The cell-scaffold constructs $(\mathrm{n}=4)$ were incubated in $1 \mathrm{~mL}$ of Trizol reagent (Thermo Fisher Scientific) for $10 \mathrm{~min}$ at room temperature and then manually disrupted and homogenized by pipetting. Thereafter, the samples were centrifuged $(12,000 \mathrm{rcf}$ for $10 \mathrm{~min}$ at $4^{\circ} \mathrm{C}$ ), and the supernatant was used for total RNA isolation. One microgram of total RNA was reverse transcribed into cDNA with TaqMan reverse transcription reagents and amplification reactions were performed with TaqMan reagents (7500 Real-Time PCR System). The following TaqMan primers (Thermo Fisher Scientific) were used: DSPP (Hs00171962_m1); DMP-1 (Hs01009391_g1); BMP-2 (Hs00154192_m1); TNF- $\alpha$ (Hs01113624_g1); IL-1 $\beta$ (Hs01555410_m1); MMP-9 (Hs00234579_m1); GAPDH (Hs99999905_m1). For BMP-2, analysis was performed at d14 and $\mathrm{d} 28$. For the other genes, the analysis was performed only at $\mathrm{d} 28$. Data was calculated by using the $2^{\Delta \Delta \mathrm{CT}}$ method. GAPDH was used as endogenous control for each gene.

\subsubsection{Immunofluorescence staining}

The expression of DSP and DMP-1 $(n=2)$ was evaluated at $\mathrm{d} 28$ on $0.5 \mu \mathrm{m}$ frozen slides. The samples were permeabilized in $0.1 \%$ Triton X, blocked in 2\% BSA and incubated with the primary antibodies (1:50 2\% BSA; Santa Cruz) overnight at $4{ }^{\circ} \mathrm{C}$. Then, the slides were washed and incubated for $1 \mathrm{~h}$ at room temperature with phycoerythrin (PE)-conjugated secondary antibody (1:100 2\% BSA; Santa Cruz), covered with DAPI mounting medium (Thermo Fisher Scientific) and imaged using a confocal fluorescence microscope (Nikon Eclipse C1 Plus).

\subsection{Angiogenesis assays}

In order to evaluate the angiogenic potential of the DPSCs seeded onto NF-PLLA scaffolds in combination with simvastatin, co-culture assays with human umbilical vein endothelial cells (HUVEC; Thermo Fisher Scientific) were performed $(n=4)$. The HUVECs $\left(1 \times 10^{5}\right.$ cells) were seeded on growth factor reduced Matrigel (Corning) pre-treated 24-well plates, in $500 \mu \mathrm{L}$ of $2 \%$ FBS endothelial medium (Lonza, Walkersville, MD, USA) with no endothelial growth factor supplementation. Immediately thereafter, the DPSC/NF-PLLA scaffold construct was placed on a permeable polycarbonate membrane transwell support with a $0.4 \mu \mathrm{m}$ pore size (Corning), and $300 \mu \mathrm{L}$ of osteogenic medium supplemented with or without LPS with or without simvastatin was added, as described in Table 1. The transwell was placed onto the HUVECs and the co-culture was incubated at $37{ }^{\circ} \mathrm{C}$ and $5 \% \mathrm{CO}_{2}$ for $24 \mathrm{~h}$. After that, the HUVECs were stained with $2 \mu \mathrm{g} / \mathrm{mL}$ Calcein AM (Thermo Fisher Scientific) and the vessel-like structures were observed under confocal fluorescence microscopy. A total of 4 images per sample were obtained, and the tube length and number of connections were calculated using Imagej. In order to observe the angiogenic potential of HUVECs on NF-PLLA scaffolds, $5 \times 10^{6}$ HUVECs were seeded onto the scaffolds $(5 \mathrm{~mm}$ diameter, $1 \mathrm{~mm}$ thickness) and placed on the bottom of 24-well plates in endothelial medium containing $2 \%$ FBS. The resulting indirect co-culture of HUVECs and DPSC/FN-PLLA scaffolds were incubated together for 24 h. Finally, the HUVEC/NF-PLLA scaffold constructs $(n=2)$ were fixed in $4 \%$ paraformaldehyde (PFA) and embedded in an O.C.T compound. $0.5 \mu \mathrm{m}$ thick frozen slides were then cut and stained with F-actin, as previously described. In addition, for both DPSCs and HUVECs, the gene expression $(\mathrm{n}=4)$ of VEGF (TaqMan assay \# Hs00900055_m1) was evaluated using real-time PCR, as previously described. For both assays, HUVECs cultured in endothelial medium with or without VEGF (100 ng/mL; Lonza) were used as negative and positive control groups, respectively.

\subsection{Subcutaneous implantation}

The cell/scaffold constructs were prepared as previously described. The constructs were incubated with or without LPS $(10 \mu \mathrm{g} / \mathrm{mL})$ for 1 week, and then incubated with simvastatin for 2 weeks in vitro, following the established experimental design. At $\mathrm{d} 14$, the scaffolds were implanted into subcutaneous pockets surgically created in nude (nu/nu) mice (age 6-8 weeks). The animal surgical procedure was approved by the University Committee of Use and Care of Animals (UCUCA) at the University of Michigan. Surgery was performed under general inhalation anesthesia with isofluorane. Four subcutaneous pockets were created using blunt dissection, and one cell-scaffold construct for each group (Table 1) was implanted into each pocket $(n=4)$. After implantation, the incisions were closed with staples. Animals were euthanized and samples were retrieved after 8 weeks. Harvested specimens were immediately fixed with $10 \%$ formalin $(n=2)$ or $4 \%$ PFA $(n=2)$ for $24 \mathrm{~h}$ at $4{ }^{\circ} \mathrm{C}$. Formalin-fixed samples were processed in paraffin and then subjected to hematoxylin-eosin (H\&E), Masson's tri- 
chrome and von Kossa staining. Frozen slides (PFA-fixed samples) was used to perform immunohistochemistry for DSP. The antimouse Cell and Tissue Staining Kit (HRP-AEC System, R\&D Systems, Minneapolis, MN, USA) was used to stain the slides incubated with primary mouse anti-human DSP antibody (1:100 2\% BSA, Santa Cruz Biotechnology). All procedures were performed according to the manufacturer's instruction.

\subsection{Statistical analysis}

The experiments were performed twice to ensure reproducibility. Data was analyzed by two-way ANOVA complemented by Tukey's test to determine the significant differences between the study groups. A value of $p<.05$ was considered to be statistically significant.

\section{Results}

\subsection{Dental pulp cells}

Fig. 1 shows representative images of stem cell markers positively stained in the dental pulp cell (DPC) culture at passage \# 3. This culture featured $22.8 \%( \pm 6.6), 94.1 \%( \pm 1.2)$, and $70.3 \%$ $( \pm 7.5)$ of positive cells for CD-146, OCT3/4 and STRO-1, respectively. According to Aiyama et al. [40] and Gronthos et al. [36], primary culture of pulp tissue with a population of cells positive for these markers is capable of multilineage (adipogenic, chondrogenic and osteogenic) differentiation in vitro and after subcutaneous implantation in vivo.

\subsection{Establishment of experimental design}

To demonstrate the protective role of simvastatin on DPSCs in the presence of an inflammatory stimulus, we selected a LPS concentration sufficient for interfering negatively with the capability of these cells to deposit mineralized matrix. As observed in Fig. 3a, the treatment of DPSCs with 1 and $10 \mu \mathrm{g} / \mathrm{mL}$ LPS caused a reduction in calcium deposition in a concentration dependent fashion, with no negative effects on cell viability/proliferation (Fig. 3b). Next, the DPSCs were pre-treated with $10 \mu \mathrm{g} / \mathrm{mL}$ LPS for 7 days in order to simulate an inflammatory condition in vitro. As indicated in Fig. 2, the cells were seeded at d-7, followed by further cultivation in culture medium supplemented with or without LPS for 7 days. From this time (d0), the cells were cultivated in osteo- genic medium supplemented with or without LPS and/or simvastatin, and cells were analyzed at 14 or 28 days after d0 (d14 or d28).

\subsubsection{Anti-inflammatory potential}

The LPS treatment resulted in TNF- $\alpha$ overexpression at d0 (Fig. 4a). Nevertheless, the co-treatment of LPS-induced cells with simvastatin led to a reduction in TNF- $\alpha$ gene expression at $\mathrm{d} 14$.

\subsubsection{Odontogenic potential}

The expression of odontoblastic markers also demonstrates the positive effect that simvastatin exerted on LPS-induced DPSCs. Cells pre-treated and cultivated in LPS resulted in an intense reduction in ALP activity (Fig. 4b) and Ca deposition (Fig. 4c). However, concomitant treatment with simvastatin following the pretreatment time with LPS minimized this effect: the LPS+/SIM+ group showed significantly higher expression of these markers than the LPS+/SIM - group. On the other hand, an absence of any significant difference between SIM+/LPS+ and the negative control was observed for Ca deposition, indicating that the positive effect of simvastatin balanced the negative effect of LPS under the selected conditions. Understandably, the ALP activity and Ca deposition in the positive simvastatin only group (LPS-/SIM+ group) were significantly higher than those observed for the group with both positive and negative stimuli (LPS+/SIM+ group).

\subsection{Anti-inflammatory signaling pathways for simvastatin mediated cytoprotection of LPS-induced DPSCS}

Cells cultivated with LPS showed significantly higher expression of pNFkBp65 relative to the negative control (LPS-/SIM-) and simvastatin-treated (LPS-/SIM+) groups (Fig. 5a and c). On the other hand, the concomitant treatment of DPSCs with LPS and simvastatin (LPS+/SIM+) significantly reduced the expression of this protein in comparison to cells treated only with LPS. Treatment of cells with LPS also downregulated the expression of PPRA $\gamma$; however, simvastatin was able to revert this effect (Fig. 5b and c).

\subsection{Signaling pathways for simvastatin mediated odontogenic differentiation of DPSCS}

To investigate the signaling pathways for odontoblastic differentiation, we detected that LPS downregulated phosphorylation of ERK1/2 and Smad1 (Fig. 6a\&b); nevertheless, treatment with (a)

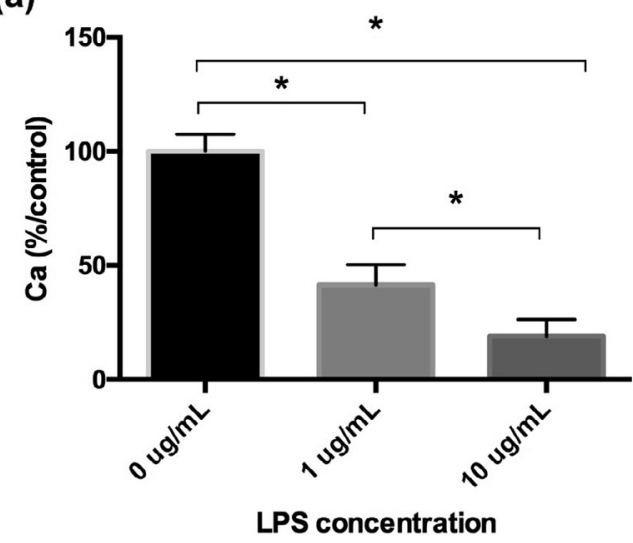

(b)

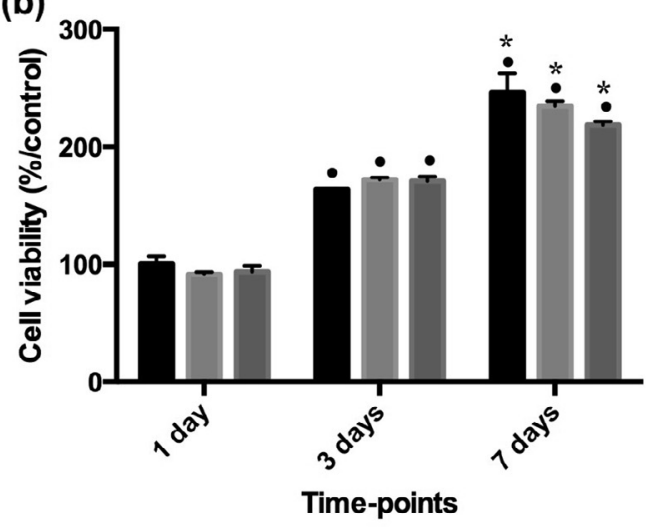

LPS concentration

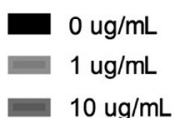


(a)

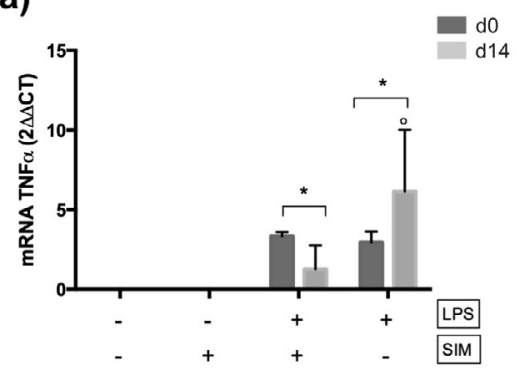

(b)

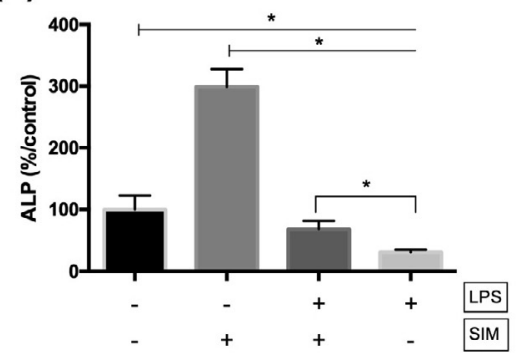

(c)

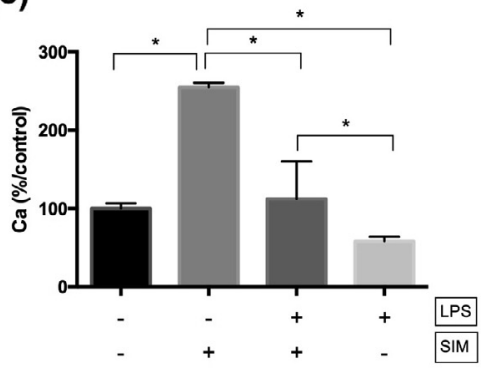

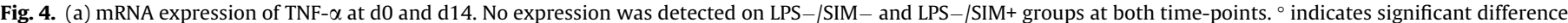

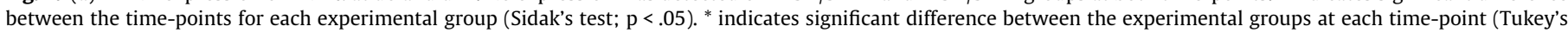

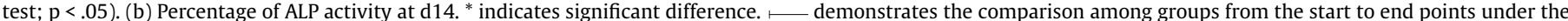

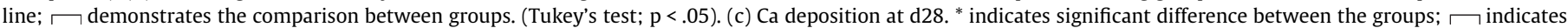
the comparison between groups (Tukey's test; $\mathrm{p}<.05$ ).

(a)

(b)
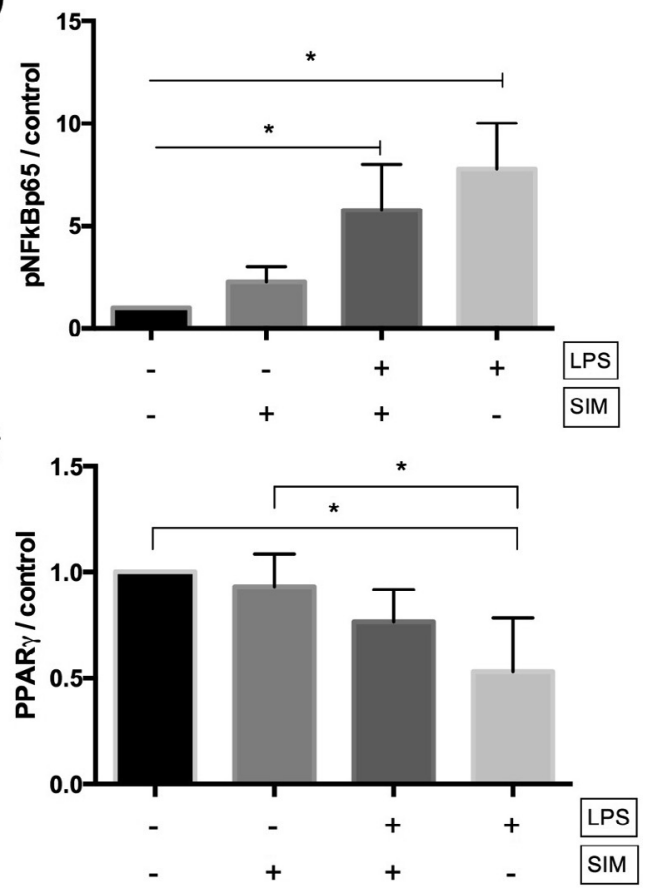

(c)
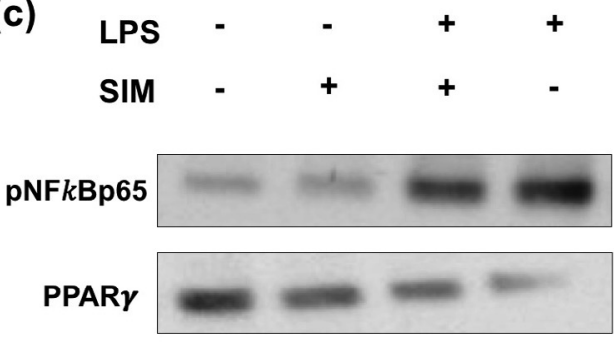

$\beta$-Actin

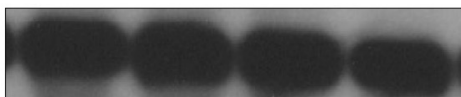

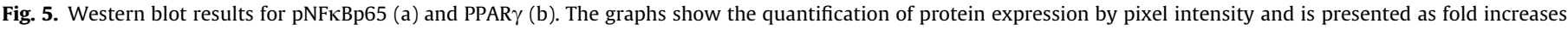

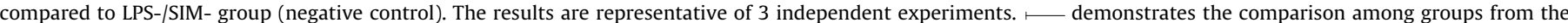

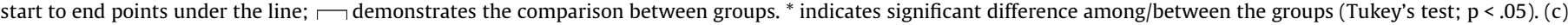
Representative bands obtained by western blot assay.

simvastatin rescued the phenotype, as the LPS+/SIM+ group showed significantly higher phosphorylation of these proteins vs. the LPS+/SIM - group and no significant difference with the negative control LPS-/SIM- group (Fig. 6c\&d). No differences in pSmad2/3 expression were detected among these groups (Fig. 6e\&f).

\subsection{Effect of simvastatin and LPS on DPSCs seeded onto NF-scaffolds.}

\subsubsection{Cell attachment and proliferation}

NF-PLLA scaffolds with a well-defined macroporous structure and nanofibrous architecture (50-500 nm fiber diameter) were fabricated (Fig. 7a). Differences in cell adhesion and spreading on NF-PLLA scaffolds under different experimental conditions were qualitatively assessed by fluorescence confocal microscopy after cytoskeleton structure staining (Fig. 7b). Immediately after seeding (d-7), DPSCs were located inside the interconnected macropore structures. Following the pre-treatment period (d0), it was clear that cells cultured with LPS exhibited morphological differences in cytoskeleton organization in comparison with cells cultured in medium without LPS supplementation. A similar pattern was observed at d14 and d28, with cells cultured with LPS exhibiting lower spreading on the NF-PLLA scaffold when compared to the LPS-free control; however, cells cultured with simvastatin had the capability to spread over larger areas on NF-PLLA scaffolds. The DNA assay revealed that the pre-treatment with LPS had no effect on cell proliferation groups at d0 (Fig. 7c). Nevertheless, supplementation with simvastatin seems to have diminished the proliferative potential of DPSCs at later periods. The DNA concentration was significantly lower in the LPS-/SIM+ group at 
(a)

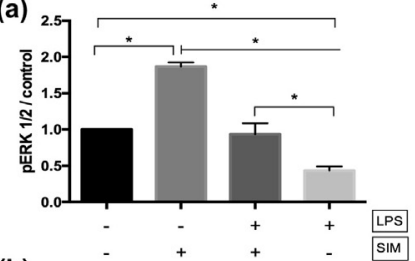

(b)

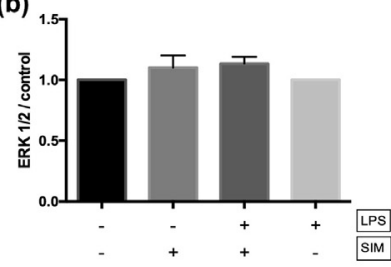

(c)

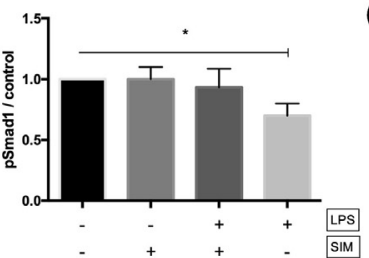

(d)

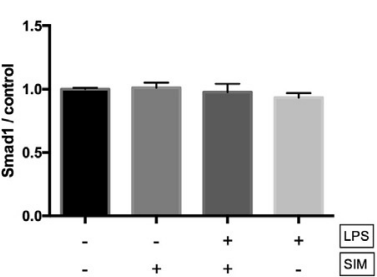

(e)

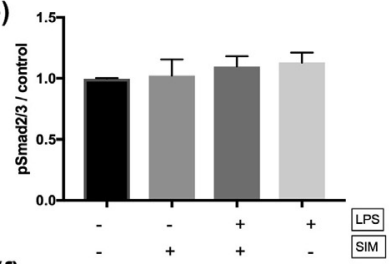

(f)

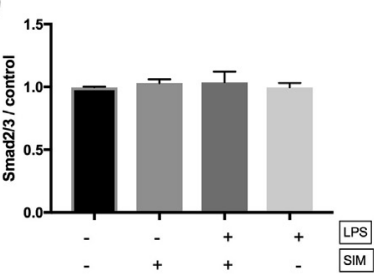

(g)

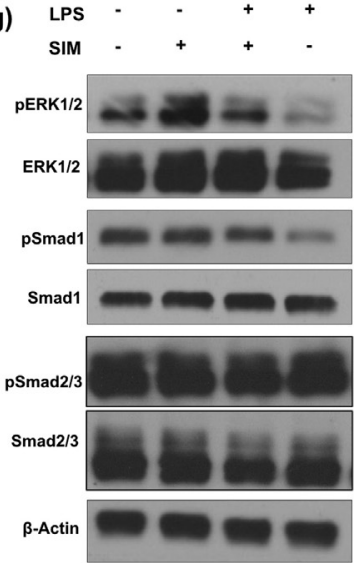

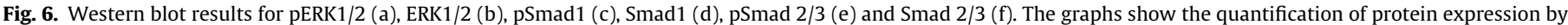

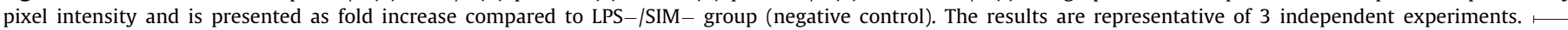

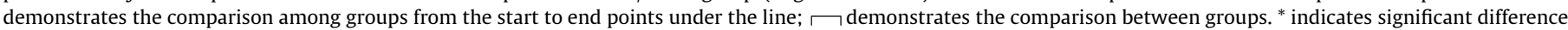
among/between the groups (Tukey's test; $\mathrm{p}<.05$ ). (g) Representative bands obtained by Western blot assay.

(a) Microtopography

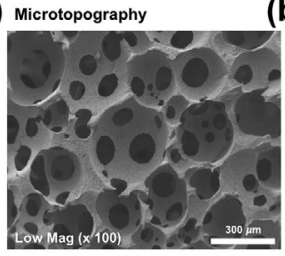

Nanotopography (pore wall)

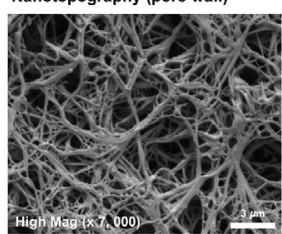

(b) $d-7$
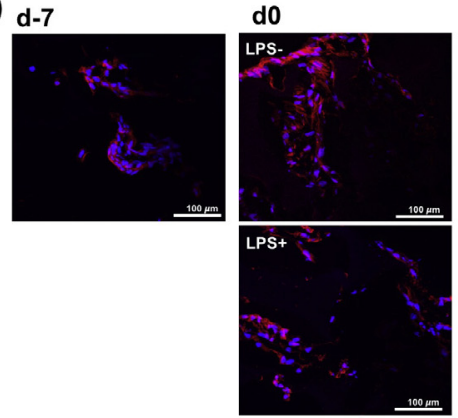

d14

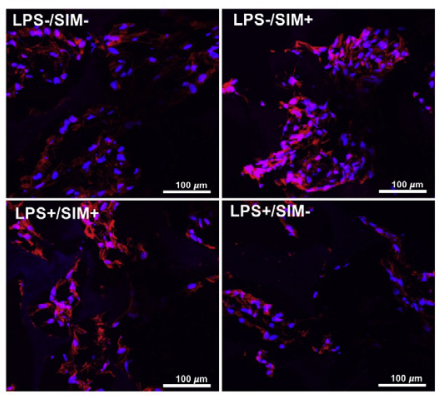

d28

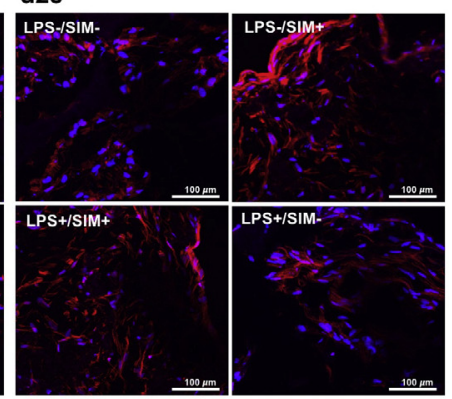

(c)

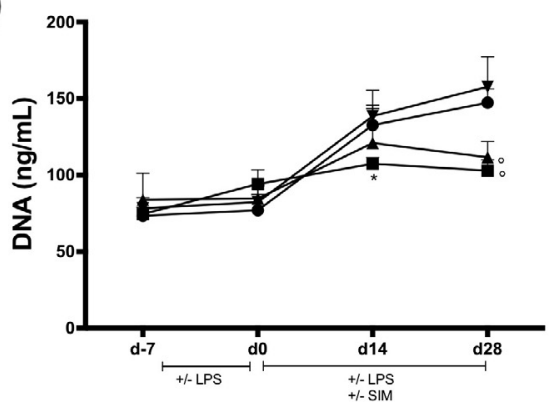

- -LPS/-SIM

- - LPS/+SIM

^ +LPS/+SIM

$*+$ LPS/-SIM

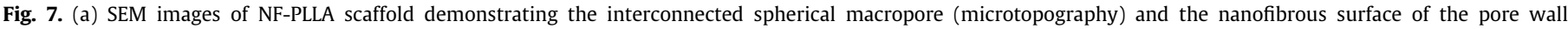

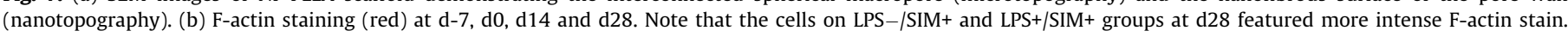

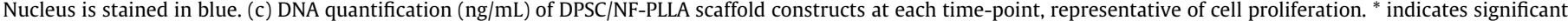

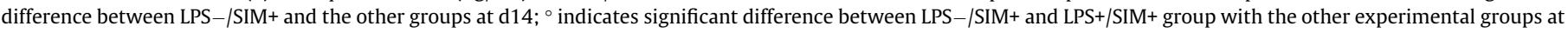
$\mathrm{d} 28$ (Tukey's test; $\mathrm{p}<.05$ ). (For interpretation of the references to colour in this figure legend, the reader is referred to the web version of this article.)

$\mathrm{d} 14$ and $\mathrm{d} 28$ than in the other experimental groups. This effect was also observed for the LPS+/SIM+ group at d28.

\subsubsection{Inflammatory markers overexpression}

Treatment of DPSCs/NF-PLLA scaffold constructs with LPS (LPS $+/$ SIM - group) resulted in intense overexpression of TNF- $\alpha$, IL-1 $\beta$ and MMP-9 mRNA at d28 in comparison with a negative control group (LPS-/SIM-) (Fig. 8). The concomitant treatment of cells with LPS and simvastatin following the pre-treatment time minimized the overexpression of these pro-inflammatory mediators.

\subsubsection{In vitro differentiation}

As expected, LPS down-regulated odontoblastic markers expression at d14 and d28. The ALP activity (Fig. 9a) and Ca deposition (Fig. 9b) values measured for the LPS+/SIM- group were significantly lower than those measured in the other experimental groups. Simvastatin alone significantly enhanced both ALP activity and Ca deposition in comparison with the negative control. When LPS and simvastatin were added together to the cells (LPS+/SIM+), ALP activity and $\mathrm{Ca}$ concentration rebounded significantly compared to the LPS+/SIM - group, with the Ca concentration recovering to about the same as the negative control group. The results of von Kossa staining corroborate these data (Fig. 9f). A small amount 

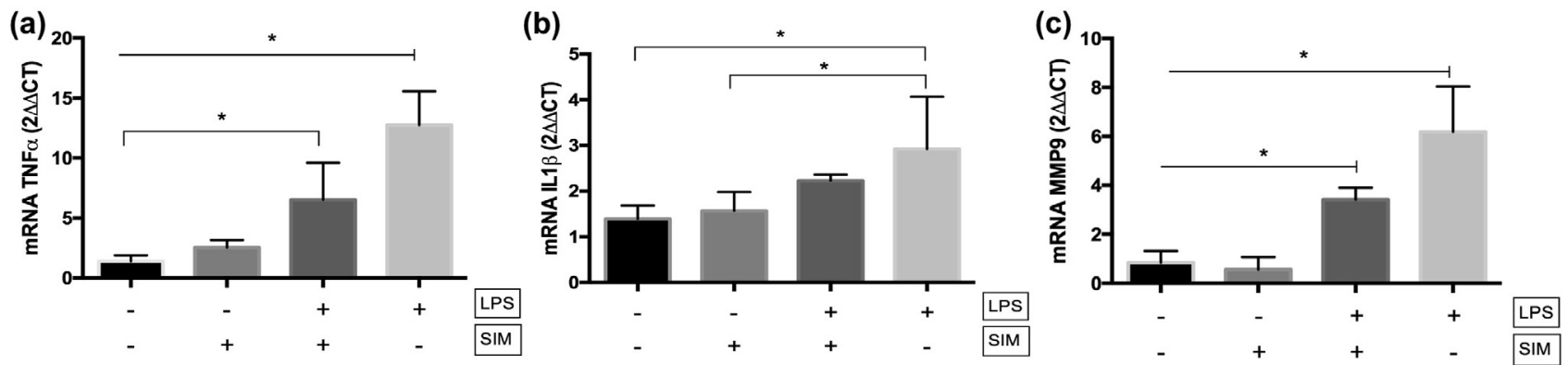

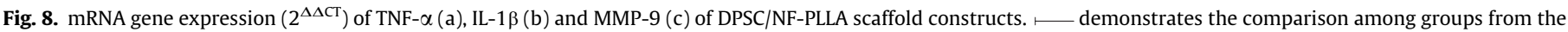
start to end points under the line; $\square$ demonstrates the comparison between groups. * indicates significant difference among/between groups (Tukey's test; $\mathrm{p}<.05$ ).

(a)

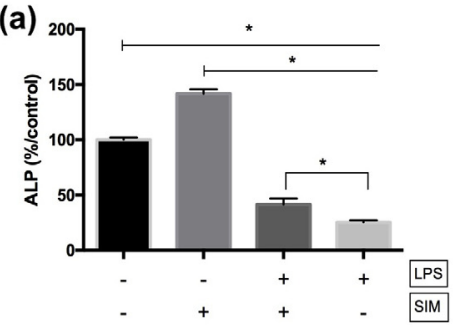

(c)

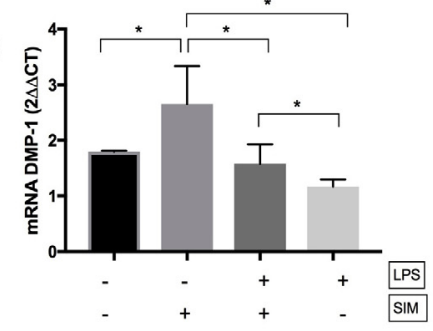

(f)

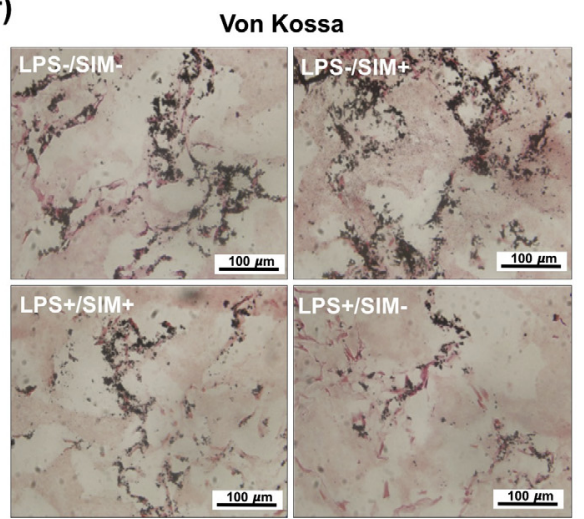

(d)
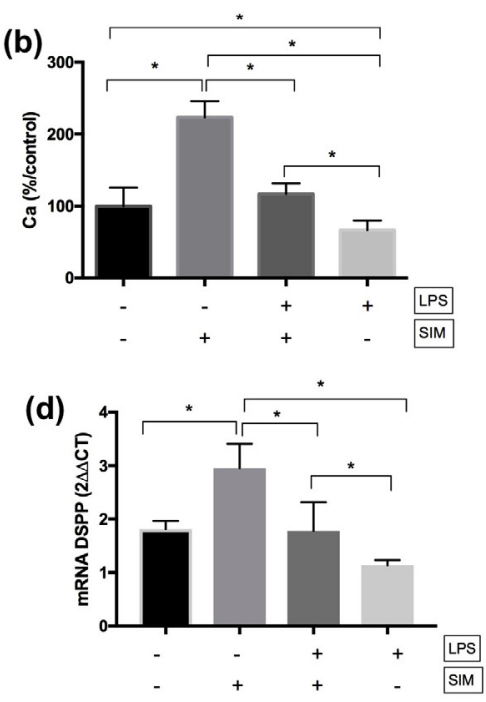

Immunofluorescence DMP-1

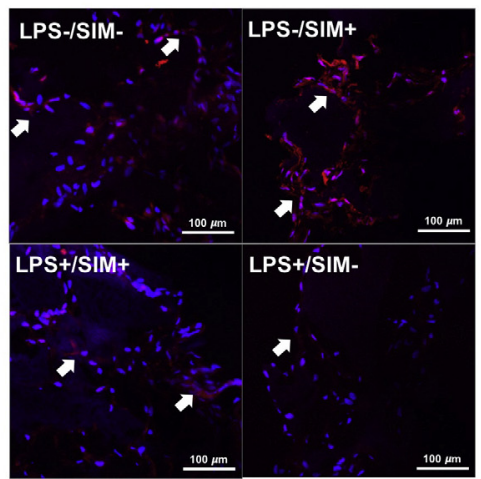

(e)

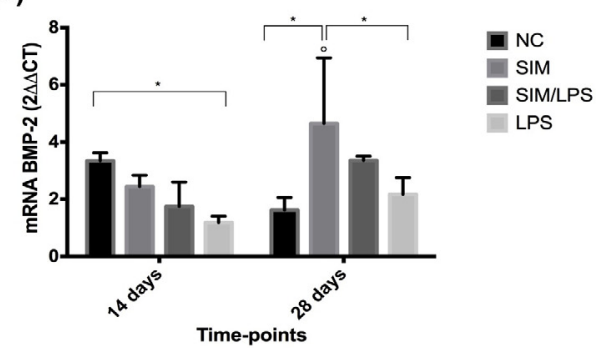

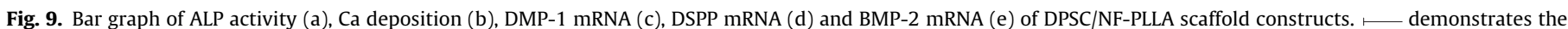

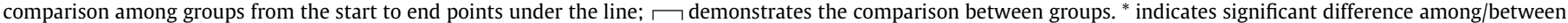

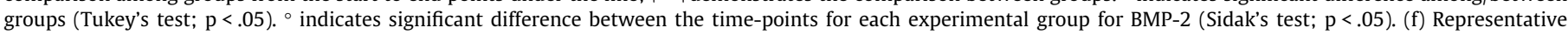
images from histological staining for samples of each group at $\mathrm{d} 28$. Arrows point to positive staining for DMP-1 and DSP.

of calcium was detected for the LPS only group, whereas simvastatin-treated cells demonstrated intense mineral deposition. A similar intensity in calcium staining was detected for the negative control and LPS+/SIM+ group, demonstrating that simvastatin played a positive role in mineralized matrix deposition by DPSCs seeded onto NF-PLLA scaffolds under in vitro inflammation conditions (LPS+). The gene expression profiles of DSPP (Fig. 9c) and DMP-1 (Fig. 9d) at d28 revealed a similar pattern, with simvastatin leading to intense overexpression of these genes in comparison to a negative control, and LPS resulting in significant down- regulation. Concomitant treatment of DPSCs with LPS and simvastatin (LPS+/SIM+) resulted in higher DSPP mRNA expression in comparison with those cells exposed to LPS only (LPS+/SIM-). Also, no significant difference between the negative control group and the LPS+/SIM+ group was observed for either DMP-1 or DSPP mRNA expression. Immunofluorescence staining intensity measurement revealed that the protein expression level of DSPP was clearly higher in the LPS+/SIM+ group than in the LPS+/SIMgroup. However, only slight increase in DMP-1 protein expression was observed in the LPS+/SIM+ group than in the LPS+/SIM- group. 
Finally, we also measured the gene expression of BMP-2 (Fig. 9e) in order to determine what role simvastatin plays in modulating the BMP-2 pathway. At day 14, only cells in the LPS+/SIMgroup displayed a significant reduction in BMP-2 gene expression in comparison to the negative control. No significant difference was observed when the LPS-/SIM-, LPS-/SIM+ and LPS+/SIM+ groups were compared at this time-point. Importantly, a substantial increase in BMP-2 gene expression was observed in the LPS-/ $\mathrm{SIM}+$ group over a longer period of time (from day 14 to day 28), but such increase in BMP-2 gene expression was not observed in the LPS-/SIM - control group over the same period of time. At day 28, a significantly higher BMP-2 gene expression level was observed in the LPS-/SIM+ group than in the negative control group, suggesting the cells entering an odontogenic phase with the longer time of simvastatin treatment. Although a higher level of BMP-2 gene expression was also observed in the LPS+/SIM+ group than in the LPS+/SIM - group at day 28, the difference was not statistically significant. Similarly, BMP-2 expression was also higher in the LPS+/SIM+ group than in the LPS-/SIM+ at $\mathrm{d} 28$, but there was no statistically significant difference between these two groups.

\subsection{Angiogenesis assay}

To determine the angiogenic potential of DPSC/NF-PLLA scaffold constructs in the presence of simvastatin and/or LPS, we performed co-culture assays with HUVECs in vitro. All tested experimental conditions increased the tube length of HUVECs seeded on Matrigel, in comparison to the negative control (Fig. 10a). The number of junctions was also higher when the DPSCs were cultivated in the presence of LPS and/or simvastatin (Fig. 10b). More interconnected angiogenic structures of HUVECs were observed in the LPS-/SIM+, LPS+/SIM+ and LPS+/SIM - groups, which were similar to a positive control group (VEGF) (Fig. 10c). VEGF gene expression was significantly increased in DPSC/NF-PLLA scaffold constructs when cultured with simvastatin (whether or not LPS was also present). Therefore, we hypothesize that endogenously expressed VEGF by DPSCs played a fundamental role in promoting the angiogenic potential of HUVECs under this in vitro set up. In order to determine the capability of endothelial cells to form vessel-like structures inside the scaffold, we performed the same assay with the HUVECs seeded onto the NF-PLLA scaffolds. The HUVEC/NFPLLA scaffolds construct showed significantly higher VEGF gene expression when the DPSC/NF-PLLA construct was maintained in the presence of LPS and/or simvastatin (Fig. 10e). Additionally, the HUVECs were able to form vessel-like structures inside the NF-PLLA scaffolds, which were more frequent when the DPSCs were incubated with LPS and/or simvastatin (Fig. 10f).

\subsection{In vivo analysis}

The H\&E staining sections showed that cells were present in the scaffold macropores for all groups. Vascular structures were observed inside the scaffolds, which were more frequently found when the cells were cultivated in the presence of LPS and/or simvastatin. We also observed a large amount of extracellular matrix surrounding the cells inside the scaffold macropores, especially for the LPS-/SIM - and LPS-/SIM+ groups (Fig. 11a). Masson's trichrome staining revealed a collagen-rich matrix surrounded by cells in the scaffold's macropores. The presence of this collagenous matrix was reduced in the LPS+/SIM+ group and almost absent in the LPS+/SIM - group (Fig. 11b). Immunohistochemical analysis of DSP clearly revealed the presence of positive cells among the LPS-/SIM-, LPS-/SIM+ and LPS+/SIM+ groups. Within these conditions, the LPS-/SIM+ group featured the most intense DSP staining, while the staining was minimal on the LPS+/SIM - group (Fig. 11c). Finally, von Kossa staining uncovered large mineral structures were found inside the scaffold macropores in those groups in which the cells were not exposed to LPS. Smaller mineralized structures were found in the LPS+/SIM+ group. Scarce and weakly stained structures were present in the LPS+/SIM- group (Fig. 11d).

\section{Discussion}

While advanced biomimetic scaffolds can play a substantial role in facilitating tissue regeneration $[8,10]$, scaffolds alone are often of limited capacity in regulating precursor cell differentiation, where (a)

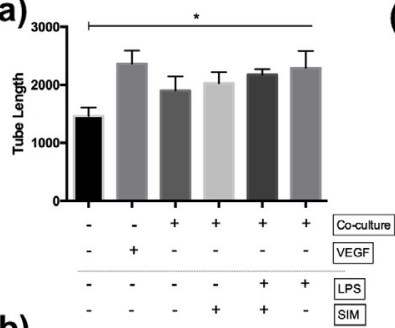

(b)

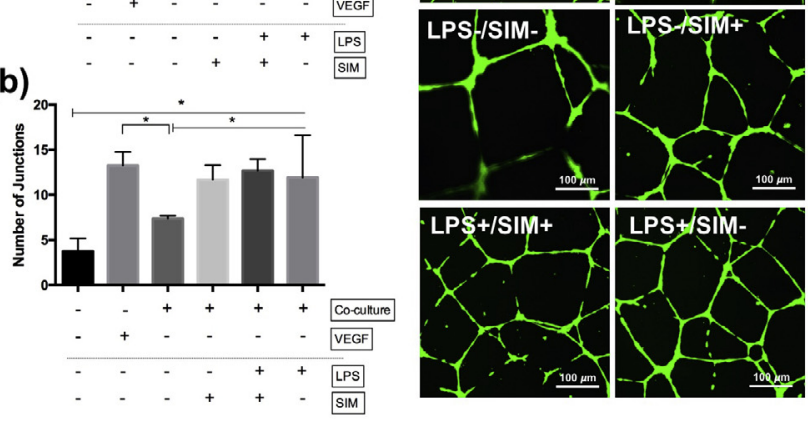

(c)
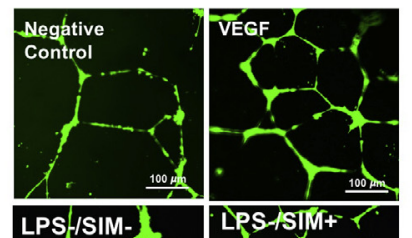

(d)

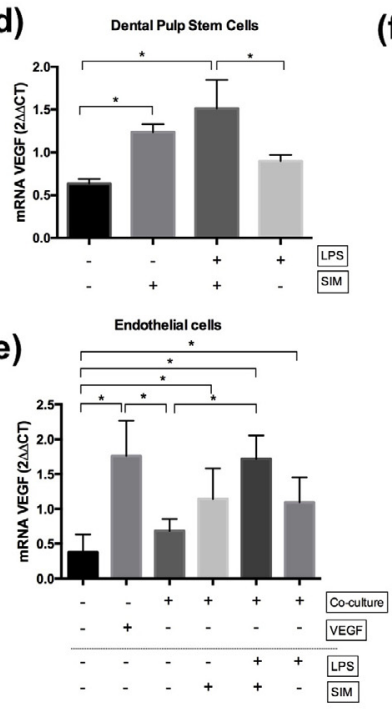

(f)

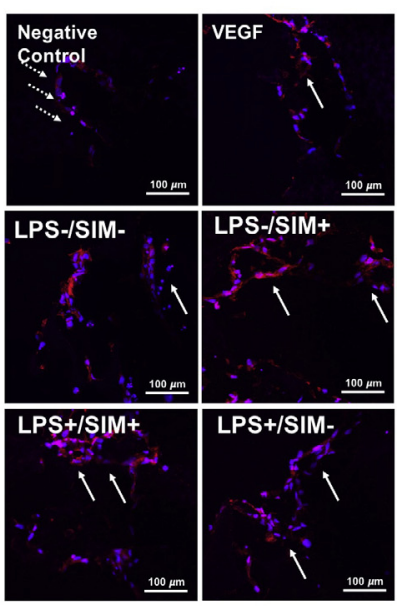

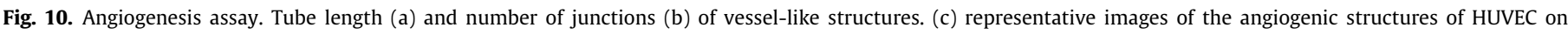

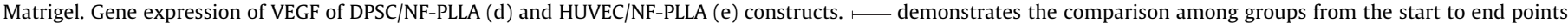

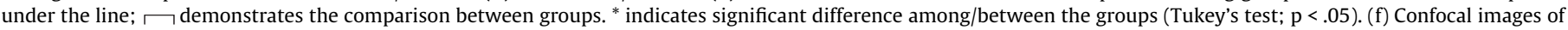
F-actin staining of HUVECs on NF-PLLA scaffolds. Dotted arrows highlight HUVECs adhered to the pore wall. Solid arrows point to the vessel-like structures. 


\section{LPS \\ SIM

$\begin{array}{ll}- & - \\ - & +\end{array}$

$-$
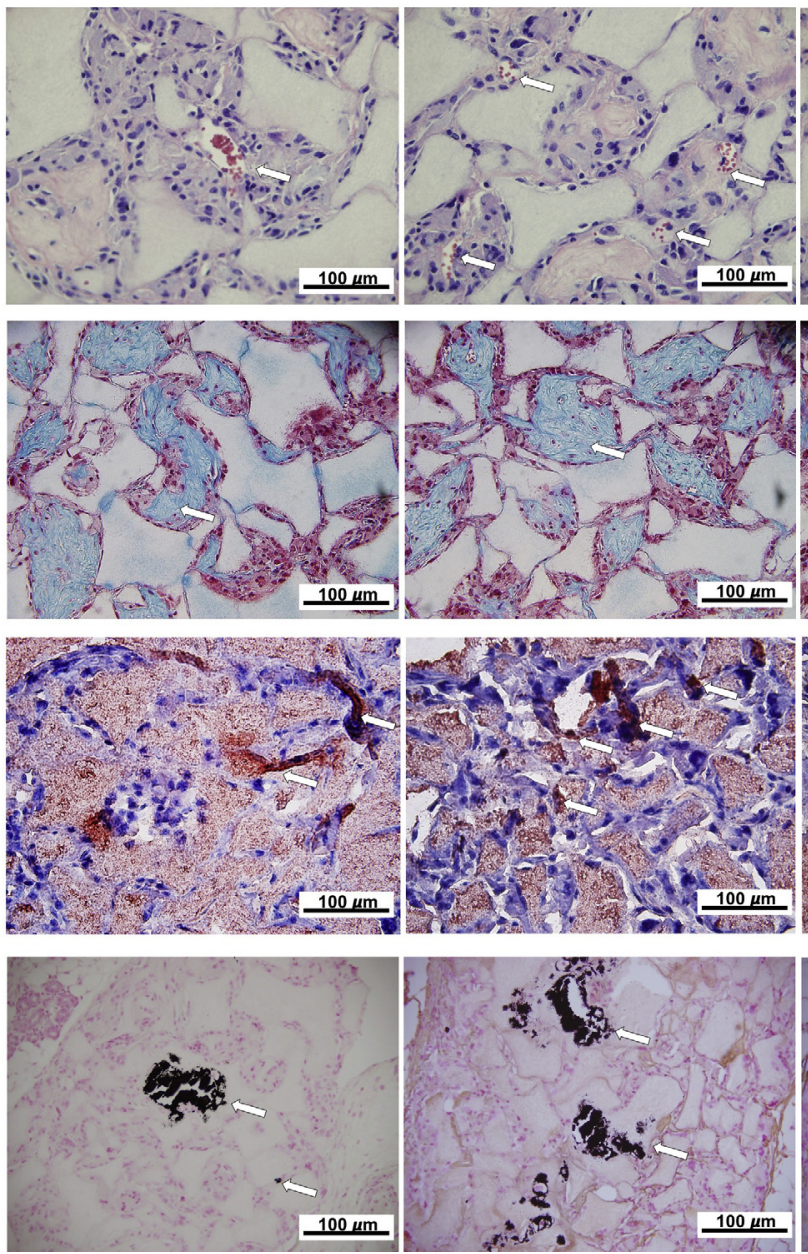
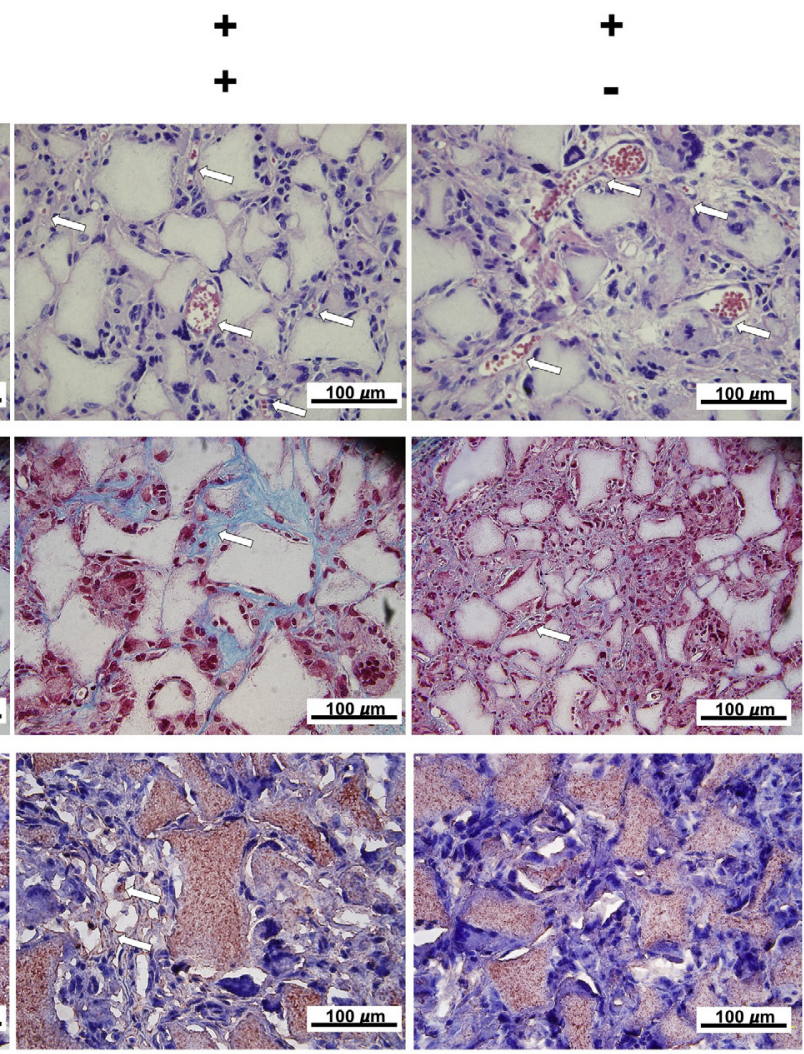

(d)
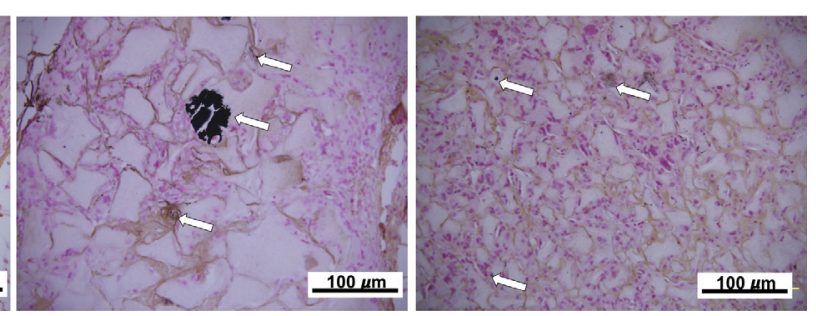

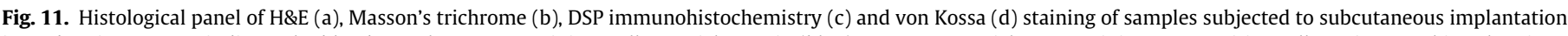

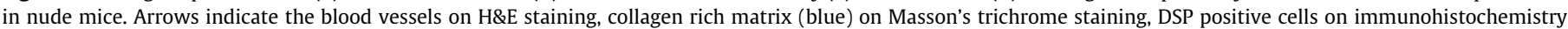

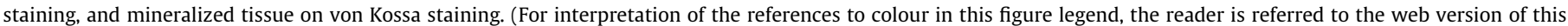
article.)

biological factors are required $[41,42]$. Simvastatin has been shown to facilitate the differentiation of dental pulp cells into highly secretive odontoblast-like cells [22,23,37]. Interestingly, in addition to the well-known functions in lipid-level regulation and odontogenic differentiation, statins have been reported to have many other effects, including improving endothelial function, decreasing inflammation, inhibiting thrombogenic response and so forth, dependent on the statin dose and the way of application $[18,19]$. We hypothesized that the presentation of simvastatin in conjunction with using a NF-PLLA scaffold may provide a favorable odontogenic and anti-inflammatory environment for LPS-induced inflammatory DPCs to achieve effective dentin regeneration. To this end, we created an in vitro simulation of pre-existent degenerative inflammation by applying an experimentally selected dose of LPS $(10 \mu \mathrm{g} / \mathrm{mL})$ that is capable of diminishing the ability of DPCs to deposit mineralized matrix ( $>80 \%$ of Ca reduction). Then, cultured cells were pre-treated with LPS for 7 days followed by incubation in osteogenic medium supplemented with or without LPS and/or simvastatin, allowing us to assess the regenerative potential of DPCs under persistent inflammation. A very low concentration of simvastatin $(0.1 \mu \mathrm{M})$ was selected as previous studies demonstrated that mineralized matrix deposition by DPCs was significantly enhanced by low-dosage simvastatin [22,23,37].
Subsequently, we discovered that pretreatment with LPS led to a threefold increase in TNF- $\alpha$ mRNA expression. Nevertheless, cultivating DPCs in osteogenic medium supplemented with LPS lowered both ALP activity and Ca deposition. Under this experimental set up, culturing DPCs with simvastatin and LPS resulted in a reduction of TNF- $\alpha$ gene expression. Additionally, simvastatin partially rescued ALP activity and Ca deposition in LPS-induced cells. Thus, we used this experimental set-up to test the simvastatin effect on dentin regeneration in our DPC/NF-PLLA scaffold 3D constructs.

We first confirmed that DPCs were capable of migrating and proliferating inside the macropores of NF-PLLA scaffolds as previously reported $[1,17]$. A reduced cell proliferation at late periods (d14 and d28) was observed in SIM-treated groups. Okamoto et al. [23] also observed late cell proliferation reduction when DPCs were cultivated with low-dosage simvastatin. This effect was correlated with a decrease of the peak of the cells in the G2/M phase; however, no accumulation of the cells in the apoptotic sub-G1 phase was observed in the simvastatin-treated cells. The authors also detected similar percentage of dead cells as in negative control, demonstrating that the reduced cell proliferation mediated by simvastatin was not correlated with a cytotoxic effect. Simvastatin elicited an odontoblastic phenotype, with cells showing sig- 
nificantly higher ALP activity and upregulation of DSPP, DMP-1 and BMP-2, along with an increase in Ca deposition. In addition, confocal imaging clearly revealed an increased actin fibril density after simvastatin treatment. Actin cytoskeletal organization is crucial in regulating stem cell differentiation. It was already demonstrated that stem cells cultured on stiff matrix underwent osteogenic differentiation whereas those on a soft matrix underwent adipogenic differentiation [43-45]. Tai et al. [28] also demonstrated that simvastatin improves actin cytoskeleton organization, focal adhesion and cellular tension in bone marrow stem cells, all of which have a direct relationship with osteogenic differentiation in vitro. Therefore, we rationalize that the cell rigidity imposed by simvastatin $[28,46]$ on DPCs may have played a role in the increased odontoblastic differentiation potential.

Based on the Western blot data, the odontoblastic phenotype observed in the DPC/NF-PLLA constructs exposed to $0.1 \mu \mathrm{M}$ simvastatin can be correlated with the activation of both the ERK and Smad 1 pathways, but not Smad $2 / 3$, as this drug led to significant increases in the expression of pERK1/2 and pSmad1. The lipid lowering effect of simvastatin is related to a decrease in the production of mevalonate derivatives - in particular farnesyl pyrophosphate (FPP) and geranylgeranyl pyrophosphate (GGPP) $[18,19]$. These isoprenoids are responsible for prenylating small G proteins, such as Ras and Rho, as required for their translocation to the cell membrane and activation of the MEK/ERK signaling complex $[47,48]$. Interestingly, accumulated evidence has demonstrated that $0.01-1 \mu \mathrm{M}$ simvastatin can stimulate osteoblastic/ odontoblastic differentiation via the activation of ERK1/2 pathway by a mechanism that seems to be independent of mevalonate pathway [25-28]. Tai et al. [28] demonstrated that $1 \mu \mathrm{M}$ simvastatin induced the differentiation of bone marrow stem cells into osteoblasts by inducing an active form of RhoA and RUNX-2/BMP-2 over-expression. Gosh-Choudhury et al. [26] also observed that a lipophilic statin stimulated Ras activation in osteoblast precursor 2T3 cells, leading to phosphorylation of ERK1/2, increased BMP-2 expression and osteoblast differentiation. In addition, Chen et al. [25] demonstrated that $1 \mu \mathrm{M}$ simvastatin mediated osteoblastic differentiation by phosphorylation of ERK1/2 and Smad1, and the results were correlated with activation of cytosolic Ras. The authors also observed that Smad1 phosphorylation occurred at later periods than ERK1/2, suggesting that autocrine or paracrine BMP-2 stimulation plays an important role in osteoblastic phenotype stimulation [25]. We also detected higher BMP-2 mRNA expression on the cell/scaffold constructs incubated with simvastatin at late periods. Whereas the negative control group expressed higher level of BMP-2 at 14 days, followed by declined expression at 28 days. In contrast, cells cultured with simvastatin showed increased BMP-2 expression at 28 days.

Conflicting data on this point was provided a few years ago by Yamashita et al. [49]. The authors reported that $10 \mu \mathrm{M}$ simvastatin blocked membrane translocation of Ras/RhoA mediated by TNF- $\alpha$, which inhibited phosphorylation of ERK1/2. This effect was reverted in the presence of FPP and GGPP, demonstrating that it was due to blocking the mevalonate pathway. On the other hand, Yamashita et al. [49] also showed that simvastatin was capable of exerting a positive effect on TNF- $\alpha$ induced cells via BMP-2 signaling pathway, leading to increased expression of BMP-2 and osteoblastic differentiation. Falcone et al. [50] observed a dosedependent effect of statins on Ras activation in lung cells. A significant reduction in Ras expression was only observed for $15-30 \mu \mathrm{M}$ simvastatin and 5-30 $\mu \mathrm{M}$ rosuvastatin, which negatively affected cell viability. The anti-proliferative, proapoptotic, anti-angiogenic and anti-invasive properties of statins at high concentrations have been widely studied for inhibiting cancer cell proliferation/viability, and this effect has a direct relationship with the inhibition of mevalonate pathway [20,50]. In view of these findings, simvastatin seems to exert differential effects on molecular pathways depending on its concentration. Whereas low concentrations $(0.01-1 \mu \mathrm{M})$ directly affect Ras/Rho proteins resulting in activation of the MEK/ ERK pathway, high concentrations of simvastatin $(10-100 \mu \mathrm{M})$ can block the translocation of these small G proteins to the membrane, in a process dependent on FPP and GGPP downstream [20,49,50]. Nevertheless, at concentrations up to $10 \mu \mathrm{M}$, simvastatin is also capable of activating the Smad1 pathway, leading to autocrine BMP-2 signaling [49]. Based on our results, simvastatin had no significant effect on Smad 2/3 pathway, which plays an important role in DPCs differentiation into odontoblasts via TGF $\beta 1$ [51]. This result corroborates Mun et al. [52], who also demonstrated that simvastatin at low concentration (1-5 $\mu \mathrm{M})$ has no effect on Smad2/3 phosphorylation or collagen synthesis by fibroblasts, whereas at high concentrations (10-50 $\mu \mathrm{M})$ it had a dose-dependent suppressive effect, inhibiting fibroblastic regenerative potential. Therefore, it seems that BMP-2 and ERK1/2 signaling pathways play a pivotal role in the odontoblastic differentiation of DPCs in the presence of low-dosage simvastatin. Therefore, future investigations are needed for elucidating the underlying mechanisms by which statins elicit the osteoblast/odontoblast differentiation at different concentrations.

Based on our data, we conclude that LPS induced intense downregulation of odontoblastic markers in DPSC/NF-PLLA scaffold constructs, resulting in interference of the cells' Ca deposition capability both in vitro and in vivo. LPS-induced cell/scaffold constructs showed impaired collagenous matrix deposition (as demonstrated via Masson's Trichrome after 8 weeks of subcutaneous implantation in nude mice). Weak positive DSP staining was observed in a few cells from the LPS-treated group in both in vitro and in vivo studies. On the other hand, treatment with simvastatin partially blocked this effect, and rescued the phenotype, as treated cells had similar levels of DSPP/DMP-1 gene expression and Ca deposition as the negative control group in vitro. Simvastatin's positive effect on LPS-treated constructs was also detected in vivo: a denser collagenous matrix, DSP positive cells and mineralized tissue were observed in the LPS+/SIM+ group in comparison to the LPS+/SIMgroup. The negative effects of LPS on odontoblastic marker expression was correlated with the down-regulation of pERK $1 / 2$ and pSmad1, as detected by Western blotting. However, odontoblastic marker expression of LPS pre-treated cells was enhanced by simvastatin, demonstrating that simvastatin could revert the molecular downstream effect of LPS on vital signaling pathways related to odontoblastic differentiation.

Regarding the effect of LPS on pERK1/2 down-regulation, conflicting data are present in literature. According to several studies, LPS is an inflammatory stimulus to DPCs and leads to the overexpression of pro-inflammatory cytokines and odontoblastic markers, which have been correlated with up-regulation of pERK1/2. However, it is important to note that in these studies, lowdosage and short-term exposure to LPS was used [53-57]. Only a few studies evaluated the effect of high-dosage LPS on the osteo/ odontogenic differentiation of mesenchymal stem cells. A dosedependent effect of LPS on dental pulp cells was observed by Wang et al. [58], showing low-dosage LPS increasing ALP, BSP and DSPP expressions, whereas high-dosage LPS, such as $10 \mu \mathrm{g} / \mathrm{mL}$, showing an inhibitory effect. Liu et al. [38] also observed that continuous exposure of DPCs to $1 \mu \mathrm{g} / \mathrm{mL}$ LPS reduced ALP activity (7 days) and mineralized nodule deposition (21 days). Yamagishi et al. [59] demonstrated that 5,10 , and $20 \mu \mathrm{g} / \mathrm{mL}$ LPS resulted in a dose-dependent decrease in DSPP and OCN expression of DPCs. Nomiyama et al. [60] also observed that 10 , and $20 \mu \mathrm{g} / \mathrm{mL}$ LPS had a suppressive effect on the ALP activity, DSPP expression and mineralized nodule deposition by DPCs, in dose- and timedependent fashion. However, these authors did not investigate the role of MAPK/ERK pathway in the suppressive effect of LPS 
on cell differentiation [38,58-60]. On the other hand, Wang et al. [61] observed differential effects of LPS on ERK1/2 phosphorylation in pre-osteoblasts, with low-dosage up-regulating pERK $1 / 2$ and high-dosage down-regulating pERK1/2. However, these authors did not investigate the effect of high-dosage LPS on the expression of osteoblastic markers. Therefore, it seems that at high concentrations, LPS is capable to dysregulate MAP/ERK signaling pathway, which in turn reduces the odontogenic potential of dental pulp cells. However, future experiments should be performed for a better understanding of the underlying mechanism.

The cell/scaffold constructs cultivated in the presence of LPS showed high mRNA expression of IL-1 $\beta$, TNF- $\alpha$ and MMP-9. IL-1 $\beta$ and TNF- $\alpha$ represent archetypal pro-inflammatory cytokines that are rapidly released in infected or injured tissues [62]. Several researchers have demonstrated that high concentrations of these cytokines can suppress the regenerative capability of DPSCs since they promote an unbalanced odontoblastic phenotype, leading to reduced or even impaired mineralized matrix deposition [63-66]. MMP-9 was also found to be up-regulated in inflamed pulp tissues and periapical lesions in vivo and is thought to play crucial roles in pulpal inflammation due to its ability to degrade collagen, laminin, elastin, fibronectin and basement membrane zone-associated collagen [67]. In the present investigation, the up-regulation of these pro-inflammatory mediators was associated with the downregulation of DSPP, DMP-1, BMP-2, ALP and Ca deposition on cell/scaffolds constructs in vitro. Previous studies demonstrated that long-time treatment of DPSCs with LPS induces overexpression of pro-inflammatory cytokines associated with downregulation of odontoblastic/osteoblastic markers, in a process involving the activation of NF- $\kappa B$ and down-regulation of PPRA $\gamma$ transcription factors [43]. The treatment of DPSCs with substances capable of inactivating the NF- $\kappa B$ pathway and increasing PPRA $\gamma$ expression effectively inhibited the expression of proinflammatory genes, such as IL- $1 \beta$, TNF- $\alpha$, IL-6, IL- 8 and COX-2, and enhanced the regenerative potential of LPS-induced cells [38].

In the present investigation, we found that simvastatin led to significant down-regulation of p65 phosphorylation in LPSstimulated cells. Phosphorylation of p65 plays a key role in regulating NF- $\kappa B$ activation and nuclear translocation [62]. The ability of statins at high concentrations to inhibit the NF- $\kappa B$ transcriptional cascade activation in LPS-induced cells has been demonstrated in previous work. Chang et al. [35] observed that $50 \mu \mathrm{M}$ simvastatin down-regulated the expression of IL-1 $\beta$, IL-6, MMP-1 and MMP13 on LPS-stimulated articular chondrocytes, and this effect was correlated with a significant reduction in NF- $\kappa \mathrm{B}$ translocation to the nucleus. Ahn et al. [32] showed that $50 \mu \mathrm{M}$ simvastatin was capable of blocking NF- $\kappa \mathrm{B}$ activation on monocytes, as this drug abolished IKK activity, suppressing progression of the inflammatory cascade that modulates pro-inflammatory cytokine production. Furthermore, other researchers observed that $10-30 \mu \mathrm{M}$ simvastatin suppressed MMP-9 expression in human leukemia and lung cancer cells, which itself was mediated by repressing p65 activity $[32,33,50]$. In the present study, we observed that a very low concentration of simvastatin $(0.1 \mu \mathrm{M})$ also played a role in minimizing the LPS-evoked inflammatory response in DPSCs, partially by inhibiting the NF- $\kappa \mathrm{B}$ pathway. We also observed an up-regulation of the PPAR $\gamma$ transcription factor in simvastatintreated LPS-induced cells. This transcription factor has gained attention lately since the molecule seems to have a direct relationship with DPSC survival and differentiation under inflammation $[38,68]$. It was previously demonstrated that LPS down-regulates PPAR $\gamma$ gene expression of DPSCs, and the up-regulation of PPAR $\gamma$ gene has a direct relationship with the odontogenic differentiation of LPS-stimulated DPSCs [38]. Based on our data, one possible mechanism explaining the down-regulation of pro-inflammatory mediators and the increased expression of odontoblastic markers by simvastatin might be related to an up-regulation of PPAR $\gamma$. In view of this, our future studies will investigate the underlying mechanisms involved in the activation of this transcription factor mediated by simvastatin on LPS-induced cells.

One limitation of this study is that a monoculture of DPCs exposed to LPS was used to simulate an inflammatory situation in vitro. The inflammatory environment involves complex interactions of resident and immune system cells from both the innate and adaptive immune responses. LPS induces the synthesis and secretion of a plethora of inflammatory cytokines via activation of Toll-like receptor-4 (TLR4) on resident and immune cells [69]. Therefore, in our in vitro study, LPS should have stimulated the inflammatory effect mediated by TLR4 activation on DPCs, without its effect on immune cells and its feedback on DPCs. Feng et al. [70] reported that repeated application of LPS to DPCs promotes cellular senescence, which might have played a role in the negative effect of LPS on DPCs in the present investigation. Additionally, previous reports have shown that mesenchymal stem cells (MSCs) from pulp tissue play a role in the immunosuppression and innate inflammatory process, by regulating pro- and anti-inflammatory cytokine expressions by innate and adaptive immune cells [69,71,72]. Yazid et al. [72] demonstrated that MSCs from inflamed pulp tissue lose the immunosuppressive potential on T-cells. Whereas MSCs from healthy pulp reduced TNFa and IL-2 expressions as well as increased IL-10 expression of LPS-activated Tcells, MSCs from inflamed pulp had a minimal effect on these cytokines. Conversely, Lee et al. [71] demonstrated that MSCs from inflamed pulps retained the immunomodulatory potential on LPS-activated macrophages in vitro. Therefore, the role of simvastatin on the immunomodulation of inflammation in pulp tissue should be carefully evaluated in vivo in the future.

In the present investigation, we also evaluated the angiogenic potential of DPC/NF-PLLA constructs in the presence of simvastatin and/or LPS. Angiogenesis from the surrounding tissue mediated by scaffolds is desirable since the presence of vascular structures around and inside the scaffolds can positively promote neotissue genesis [17]. The presence of blood-vessels inside the scaffolds might improve nutrient/oxygen supply and metabolic waste removal, contributing to a better extracellular environment for DPSC growth and ECM production [1,17]. We observed that endothelial cells in co-culture with simvastatin- and LPS-treated DPC/NF-PLLA scaffolds were capable of forming highly connected vascular-like structures on a Matrigel basement membrane, accompanied by increased VEGF gene expression. However, no synergistic effect between LPS and simvastatin was observed. Significant higher VEGF gene expression in DPC/NF-PLLA construct was detected only for the LPS+/SIM+ compared with LPS+/SIMgroups. Increased expression of VEGF is clearly evident in inflamed compared to healthy pulp tissue [73]. Others have detected that $0.1 \mu \mathrm{M}$ simvastatin increases VEGF expression in DPSCs [22]. Coculture of pulp and endothelial cells also showed a positive effect on angiogenesis with increased VEGF expression in both cells [74]. Moreover, Shin et al. [75] demonstrated that treatment of DPSCs with LPS $(1 \mu \mathrm{g} / \mathrm{mL})$ and TNF- $\alpha(10 \mathrm{ng} / \mathrm{mL})$ for $24 \mathrm{~h}$ induced the expression of VEGF. In this same experiment, conditioned medium obtained from DPSCs induced tubular network formation on HUVECs seeded on Matrigel. Interestingly, Zhu et al. [21] demonstrated that low-dosage simvastatin $(0.1$ and $1 \mu \mathrm{M})$ had no synergistic effect on the angiogenesis mediated by TNF- $\alpha(1 \mathrm{ng} / \mathrm{mL})$ in HUVECs, but increased angiogenesis under hypoxia at the same concentration. The angiogenic quality of the statins is believed to depend on the stimulus, mechanisms, and microenvironmental conditions. In the present study, we evaluated the angiogenic potential of simvastatin in a co-culture model with DPCs seeded onto NF-PLLA scaffolds, more than one variable may be responsible for the disparate effects of LPS and simvastatin on HUVECs. There- 
fore, the role of simvastatin on angiogenesis under inflammatory stimulation in pulp tissue should be further evaluated to understand the mechanisms underlying the cell events. Importantly, we observed that the DPC/NF-PLLA scaffold constructs cultivated with simvastatin and/or LPS induced the development of vessellike structures mediated by endothelial cells seeded on NF-PLLA scaffolds. Furthermore, H\&E staining sections obtained from the subcutaneous implantation experiment exhibited the presence of blood vessels inside scaffolds closely associated with DPSCs. These structures were more prevalent in the constructs cultivated in contact with LPS and/or simvastatin, confirming the data from coculture assay and demonstrating that these constructs had the ability to induce angiogenesis.

Therefore, the use of low-concentration simvastatin with NFPLLA scaffolds appears to be a new way to induce the regenerative potential of DPSCs under an inflammatory environment. Some previous studies showed that scaffolds capable of releasing $0.02-1 \mu \mathrm{M}$ simvastatin within $24 \mathrm{~h}$ lead to increased ALP activity and calcium deposition in vitro, and enhanced initial callus formation, neovascularization, and cell ingrowth in the grafted bone in vivo [76,77]. However, a recent investigation showed that a PLGA/HA/ $\beta$-TCP scaffold containing high dosage simvastatin $(4 \mathrm{mg} / \mathrm{mL}=0.01 \mathrm{M})$ did not lead to bone regeneration in molar extraction sockets [31]. These conflicting reports could result from the interplay between angiogenesis and osteo/odontogenesis, since highdosage simvastatin $(10 \mu \mathrm{M})$ has been shown to inhibit endothelial cell migration and angiogenesis under inflammatory conditions [21]. Therefore, in future studies, it may be interesting to develop a biocompatible NF-PLLA scaffold that can release low-dosage of simvastatin in a sustained fashion to enhance dentin regeneration and modulate inflammatory reaction.

\section{Conclusion}

Simvastatin at low concentration has a protective effect on LPSinduced DPSC/NF-PLLA scaffold constructs. This lipid lowering molecule decreases the expression of pro-inflammatory mediators, is associated with up-regulation of odontoblastic markers, and exerts a pro-angiogenic effect on endothelial cells in vitro and in vivo.

\section{Acknowledgements}

This work was supported by National Institutes of Health of the USA (NIH/NIDCR R01DE022327) and São Paulo Research Foundation of Brazil (FAPESP \# 2014/13034-3).

\section{References}

[1] J. Wang, H. Ma, X. Jin, J. Hu, X. Liu, L. Ni, P.X. Ma, The effect of scaffold architecture on odontogenic differentiation of human dental pulp stem cells, Biomaterials 32 (31) (2011) 7822-7830.

[2] R. Kuang, Z. Zhang, X. Jin, J. Hu, M.J. Gupte, L. Ni, P.X. Ma, Nanofibrous spongy microspheres enhance odontogenic differentiation of human dental pulp stem cells, Adv. Healthc. Mater. 4 (13) (2015) 1993-2000.

[3] W. Wang, M. Dang, Z. Zhang, J. Hu, T.W. Eyster, L. Ni, P.X. Ma, Dentin regeneration by stem cells of apical papilla on injectable nanofibrous microspheres and stimulated by controlled BMP-2 release, Acta Biomater. 36 (2016) 63-72.

[4] J.S. Colombo, A.N. Moore, J.D. Hartgerink, R.N. D’Souza, Scaffolds to control inflammation and facilitate dental pulp regeneration, J. Endod. 40 (4 Suppl.) (2014) S6-S12.

[5] N. Asl Aminabadi, S. Satrab, E. Najafpour, M. Samiei, Z. Jamali, S. Shirazi, A randomized trial of direct pulp capping in primary molars using MTA compared to 3Mixtatin: a novel pulp capping biomaterial, Int. J. Paediatr. Dent. 26 (4) (2016) 281-290.

[6] P.R. Cooper, M.J. Holder, A.J. Smith, Inflammation and regeneration in the dentin-pulp complex: a double-edged sword, J. Endod. 40 (4 Suppl.) (2014) S46-S51.
[7] K.M. Woo, V.J. Chen, P.X. Ma, Nano-fibrous scaffolding architecture selectively enhances protein adsorption contributing to cell attachment, J. Biomed. Mater. Res. Part A 67 (2) (2003) 531-537.

[8] K.M. Woo, V.J. Chen, H.M. Jung, T.I. Kim, H.I. Shin, J.H. Baek, H.M. Ryoo, P.X. Ma, Comparative evaluation of nanofibrous scaffolding for bone regeneration in critical-size calvarial defects, Tissue Eng. Part A 15 (8) (2009) 2155-2162.

[9] K.M. Woo, J.H. Jun, V.J. Chen, J. Seo, J.H. Baek, H.M. Ryoo, G.S. Kim, M.J. Somerman, P.X. Ma, Nano-fibrous scaffolding promotes osteoblast differentiation and biomineralization, Biomaterials 28 (2) (2007) 335-343.

[10] P.X. Ma, Biomimetic materials for tissue engineering, Adv. Drug Deliv. Rev. 60 (2) (2008) 184-198.

[11] J. Hu, X. Liu, P.X. Ma, Induction of osteoblast differentiation phenotype on poly (L-lactic acid) nanofibrous matrix, Biomaterials 29 (28) (2008) 3815-3821.

[12] L.A. Smith, X. Liu, J. Hu, P.X. Ma, The influence of three-dimensional nanofibrous scaffolds on the osteogenic differentiation of embryonic stem cells, Biomaterials 30 (13) (2009) 2516-2522.

[13] L.A. Smith, X. Liu, J. Hu, P.X. Ma, The enhancement of human embryonic stem cell osteogenic differentiation with nano-fibrous scaffolding, Biomaterials 31 (21) (2010) 5526-5535.

[14] J. Hu, L.A. Smith, K. Feng, X. Liu, H. Sun, P.X. Ma, Response of human embryonic stem cell-derived mesenchymal stem cells to osteogenic factors and architectures of materials during in vitro osteogenesis, Tissue Eng. Part A 16 (11) (2010) 3507-3514.

[15] M.J. Gupte, P.X. Ma, Nanofibrous scaffolds for dental and craniofacial applications, J. Dent. Res. 91 (3) (2012) 227-234.

[16] X. Chatzistavrou, S. Papagerakis, P.X. Ma, P. Papagerakis, Innovative approaches to regenerate enamel and dentin, Int. J. Dent. 2012 (2012) 856470.

[17] J. Wang, X. Liu, X. Jin, H. Ma, J. Hu, L. Ni, P.X. Ma, The odontogenic differentiation of human dental pulp stem cells on nanofibrous poly(L-lactic acid) scaffolds in vitro and in vivo, Acta Biomater. 6 (10) (2010) 3856-3863.

[18] J.K. Liao, U. Laufs, Pleiotropic effects of statins, Annu. Rev. Pharmacol. Toxicol. 45 (2005) 89-118.

[19] A. Oryan, A. Kamali, A. Moshiri, Potential mechanisms and applications of statins on osteogenesis: current modalities, conflicts and future directions, J. Control. Release 215 (2015) 12-24.

[20] O. Fromigue, E. Hay, D. Modrowski, S. Bouvet, A. Jacquel, P. Auberger, P.J. Marie, RhoA GTPase inactivation by statins induces osteosarcoma cell apoptosis by inhibiting p42/p44-MAPKs-Bcl-2 signaling independently of BMP-2 and cell differentiation, Cell Death Differ. 13 (11) (2006) 1845-1856.

[21] X.Y. Zhu, E. Daghini, A.R. Chade, R. Lavi, C. Napoli, A. Lerman, L.O. Lerman, Disparate effects of simvastatin on angiogenesis during hypoxia and inflammation, Life Sci. 83 (23-24) (2008) 801-809.

[22] K.S. Min, Y.M. Lee, S.O. Hong, E.C. Kim, Simvastatin promotes odontoblastic differentiation and expression of angiogenic factors via heme oxygenase- 1 in primary cultured human dental pulp cells, J. Endod. 36 (3) (2010) 447-452.

[23] Y. Okamoto, W. Sonoyama, M. Ono, K. Akiyama, T. Fujisawa, M. Oshima, Y. Tsuchimoto, Y. Matsuka, T. Yasuda, S. Shi, T. Kuboki, Simvastatin induces the odontogenic differentiation of human dental pulp stem cells in vitro and in vivo, J. Endod. 35 (3) (2009) 367-372.

24] N. Asl Aminabadi, E. Maljaei, L. Erfanparast, A. Ala Aghbali, H. Hamishehkar, E. Najafpour, Simvastatin versus calcium hydroxide direct pulp capping of human primary molars: a randomized clinical trial, J. Dent. Res. Dent. Clin. Dent. Prospects 7 (1) (2013) 8-14.

[25] P.Y. Chen, J.S. Sun, Y.H. Tsuang, M.H. Chen, P.W. Weng, F.H. Lin, Simvastatin promotes osteoblast viability and differentiation via Ras/Smad/Erk/BMP-2 signaling pathway, Nutr. Res. 30 (3) (2010) 191-199.

[26] N. Ghosh-Choudhury, C.C. Mandal, G.G. Choudhury, Statin-induced Ras activation integrates the phosphatidylinositol 3-kinase signal to Akt and MAPK for bone morphogenetic protein-2 expression in osteoblast differentiation, J. Biol. Chem. 282 (7) (2007) 4983-4993.

[27] I.S. Kim, B.C. Jeong, O.S. Kim, Y.J. Kim, S.E. Lee, K.N. Lee, J.T. Koh, H.J. Chung, Lactone form 3-hydroxy-3-methylglutaryl-coenzyme A reductase inhibitors (statins) stimulate the osteoblastic differentiation of mouse periodontal ligament cells via the ERK pathway, J. Periodontal Res. 46 (2) (2011) 204-213.

[28] I.C. Tai, Y.H. Wang, C.H. Chen, S.C. Chuang, J.K. Chang, M.L. Ho, Simvastatin enhances Rho/actin/cell rigidity pathway contributing to mesenchymal stem cells' osteogenic differentiation, Int. J. Nanomed. 10 (2015) 5881-5894.

[29] S.K. Lin, S.H. Kok, Y.L. Lee, K.L. Hou, Y.T. Lin, M.H. Chen, C.C. Wang, C.Y. Hong, Simvastatin as a novel strategy to alleviate periapical lesions, J. Endod. 35 (5) (2009) 657-662.

[30] U. Price, H.O. Le, S.E. Powell, M.J. Schmid, D.B. Marx, Y. Zhang, D. Wang, N. Narayana, R.A. Reinhardt, Effects of local simvastatin-alendronate conjugate in preventing periodontitis bone loss, J. Periodontal Res. 48 (5) (2013) 541-548.

[31] M. Noronha Oliveira, L.H. Rau, A. Marodin, M. Correa, L.R. Correa, A. Aragones, R.S. Magini, Ridge preservation after maxillary third molar extraction using $30 \%$ porosity PLGA/HA/beta-TCP scaffolds with and without simvastatin: a pilot randomized controlled clinical trial, Implant Dent. (2017).

[32] K.S. Ahn, G. Sethi, M.M. Chaturvedi, B.B. Aggarwal, Simvastatin, 3-hydroxy-3 methylglutaryl coenzyme A reductase inhibitor, suppresses osteoclastogenesis induced by receptor activator of nuclear factor-kappaB ligand through modulation of NF-kappaB pathway, Int. J. Cancer 123 (8) (2008) 1733-1740.

[33] Y.J. Chen, L.S. Chang, Simvastatin induces NFkappaB/p65 down-regulation and JNK1/c-Jun/ATF-2 activation, leading to matrix metalloproteinase-9 (MMP-9) but not MMP-2 down-regulation in human leukemia cells, Biochem. Pharmacol. 92 (4) (2014) 530-543. 
[34] S. Kagami, H. Kanari, A. Suto, M. Fujiwara, K. Ikeda, K. Hirose, N. Watanabe, I. Iwamoto, H. Nakajima, HMG-CoA reductase inhibitor simvastatin inhibits proinflammatory cytokine production from murine mast cells, Int. Arch. Allergy Immunol. 146 (Suppl.1) (2008) 61-66.

[35] C.H. Chang, Y.M. Hsu, Y.C. Chen, F.H. Lin, S. Sadhasivam, S.T. Loo, S. Savitha, Anti-inflammatory effects of hydrophilic and lipophilic statins with hyaluronic acid against LPS-induced inflammation in porcine articular chondrocytes, J Orthop. Res. 32 (4) (2014) 557-565.

[36] S. Gronthos, A. Arthur, P.M. Bartold, S. Shi, A method to isolate and culture expand human dental pulp stem cells, Methods Mol. Biol. 698 (2011) 107-121.

[37] S.Y. Lee, K.S. Min, G.W. Choi, J.H. Park, S.H. Park, S.I. Lee, E.C. Kim, Effects of simvastain and enamel matrix derivative on Portland cement with bismut oxide-induced growth and odontoblastic differentiation in human dental pulp cells, J. Endod. 38 (3) (2012) 405-410.

[38] Z. Liu, T. Jiang, X. Wang, Y. Wang, Fluocinolone acetonide partially restores the mineralization of LPS-stimulated dental pulp cells through inhibition of NFkappaB pathway and activation of AP-1 pathway, Br. J. Pharmacol. 170 (6) (2013) 1262-1271.

[39] G. Wei, P.X. Ma, Macroporous and nanofibrous polymer scaffolds and polymer bone-like apatite composite scaffolds generated by sugar spheres, J. Biomed. Mater. Res. Part A 78 (2) (2006) 306-315.

[40] K. Akiyama, C. Chen, S. Gronthos, S. Shi, Lineage differentiation of mesenchymal stem cells from dental pulp, apical papilla, and periodontal ligament, Methods Mol. Biol. 887 (2012) 111-121.

[41] Z. Zhang, J. Hu, P.X. Ma, Nanofiber-based delivery of bioactive agents and stem cells to bone sites, Adv. Drug Deliv. Rev. 64 (12) (2012) 1129-1141.

[42] K.J. Rambhia, P.X. Ma, Controlled drug release for tissue engineering, J. Control. Release 219 (2015) 119-128.

[43] J.S. Park, J.S. Chu, A.D. Tsou, R. Diop, Z. Tang, A. Wang, S. Li, The effect of matrix stiffness on the differentiation of mesenchymal stem cells in response to TGFbeta, Biomaterials 32 (16) (2011) 3921-3930.

[44] O.F. Zouani, J. Kalisky, E. Ibarboure, M.C. Durrieu, Effect of BMP-2 from matrices of different stiffnesses for the modulation of stem cell fate, Biomaterials 34 (9) (2013) 2157-2166.

[45] S. Tan, J.Y. Fang, Z. Yang, M.E. Nimni, B. Han, The synergetic effect of hydrogel stiffness and growth factor on osteogenic differentiation, Biomaterials 35 (20) (2014) 5294-5306.

[46] L. Redondo-Morata, R. Lea Sanford, O.S. Andersen, S. Scheuring, Effect of statins on the nanomechanical properties of supported lipid bilayers, Biophys. J. 111 (2) (2016) 363-372.

[47] P.J. Roberts, C.J. Der, Targeting the Raf-MEK-ERK mitogen-activated protein kinase cascade for the treatment of cancer, Oncogene 26 (22) (2007) 3291 3310.

[48] S. Kant, W. Swat, S. Zhang, Z.Y. Zhang, B.G. Neel, R.A. Flavell, R.J. Davis, TNFstimulated MAP kinase activation mediated by a Rho family GTPase signaling pathway, Genes Dev. 25 (19) (2011) 2069-2078.

[49] M. Yamashita, F. Otsuka, T. Mukai, H. Otani, K. Inagaki, T. Miyoshi, J. Goto, M. Yamamura, H. Makino, Simvastatin antagonizes tumor necrosis factor-alpha inhibition of bone morphogenetic proteins-2-induced osteoblast differentiation by regulating Smad signaling and Ras/Rho-mitogen-activated protein kinase pathway, J. Endocrinol. 196 (3) (2008) 601-613.

[50] D. Falcone, L. Gallelli, A. Di Virgilio, L. Tucci, M. Scaramuzzino, R. Terracciano, G. Pelaia, R. Savino, Effects of simvastatin and rosuvastatin on RAS protein, matrix metalloproteinases and NF-kappaB in lung cancer and in normal pulmonary tissues, Cell Prolif. 46 (2) (2013) 172-182.

[51] P.S. Lin, H.H. Chang, C.Y. Yeh, M.C. Chang, C.P. Chan, H.Y. Kuo, H.C. Liu, W.C. Liao, P.Y. Jeng, S.Y. Yeung, J.H. Jeng, Transforming growth factor beta 1 increases collagen content, and stimulates procollagen I and tissue inhibitor of metalloproteinase-1 production of dental pulp cells: role of MEK/ERK and activin receptor-like kinase-5/Smad signaling, J. Formos. Med. Assoc. 116 (5) (2017) 351-358.

[52] J.H. Mun, Y.M. Kim, B.S. Kim, J.H. Kim, M.B. Kim, H.C. Ko, Simvastatin inhibits transforming growth factor-beta1-induced expression of type I collagen, CTGF and alpha-SMA in keloid fibroblasts, Wound Repair Regen. 22 (1) (2014) 125133.

[53] T.M. Botero, J.S. Son, D. Vodopyanov, M. Hasegawa, C.E. Shelburne, J.E. Nor, MAPK signaling is required for LPS-induced VEGF in pulp stem cells, J. Dent Res. 89 (3) (2010) 264-269.

[54] W. He, T. Qu, Q. Yu, Z. Wang, H. Lv, J. Zhang, X. Zhao, P. Wang, LPS induces IL-8 expression through TLR4, MyD88, NF-kappaB and MAPK pathways in human dental pulp stem cells, Int. Endod. J. 46 (2) (2013) 128-136.

[55] W. He, Z. Wang, Z. Luo, Q. Yu, Y. Jiang, Y. Zhang, Z. Zhou, A.J. Smith, P.R. Cooper, LPS promote the odontoblastic differentiation of human dental pulp stem cells via MAPK signaling pathway, J. Cell. Physiol. 230 (3) (2015) 554-561.
[56] Y. Huang, H. Jiang, Q. Gong, X. Li, J. Ling, Lipopolysaccharide stimulation improves the odontoblastic differentiation of human dental pulp cells, Mol. Med. Rep. 11 (5) (2015) 3547-3552.

[57] Y.J. Ko, K.Y. Kwon, K.Y. Kum, W.C. Lee, S.H. Baek, M.K. Kang, W.J. Shon, The antiinflammatory effect of human telomerase-derived peptide on P. gingivalis lipopolysaccharide-induced inflammatory cytokine production and its mechanism in human dental pulp cells, Mediators Inflamm. 2015 (2015) 385127.

[58] Y.L. Wang, K.Q. Pan, Y. Sun, J. Deng, Effect of lipopolysaccharide on the expression of ALP, BSP, DSPP in rat dental pulp cells, Shanghai Kou Qiang Yi Xue 23 (4) (2014) 431-435.

[59] V.T. Yamagishi, C.D. Torneck, S. Friedman, G.T. Huang, M. Glogauer, Blockade of TLR2 inhibits Porphyromonas gingivalis suppression of mineralized matrix formation by human dental pulp stem cells, J. Endod. 37 (6) (2011) 812-818.

[60] K. Nomiyama, C. Kitamura, T. Tsujisawa, M. Nagayoshi, T. Morotomi, M. Terashita, T. Nishihara, Effects of lipopolysaccharide on newly established rat dental pulp-derived cell line with odontoblastic properties, J. Endod. 33 (10) (2007) 1187-1191.

[61] X.C. Wang, N.J. Zhao, C. Guo, J.T. Chen, J.L. Song, L. Gao, Quercetin reversed lipopolysaccharide-induced inhibition of osteoblast differentiation through the mitogenactivated protein kinase pathway in MC3T3-E1 cells, Mol. Med. Rep. 10 (6) (2014) 3320-3326.

[62] T. Lawrence, The nuclear factor NF-kappaB pathway in inflammation, Cold Spring Harb. Perspect. Biol. 1 (6) (2009) a001651.

[63] G. Spoto, M. Fioroni, C. Rubini, D. Tripodi, M. Di Stilio, A. Piattelli, Alkaline phosphatase activity in normal and inflamed dental pulps, J. Endod. 27 (3) (2001) 180-182.

[64] K.S. Min, Y.Y. Kwon, H.J. Lee, S.K. Lee, K.H. Kang, S.K. Lee, E.C. Kim, Effects of proinflammatory cytokines on the expression of mineralization markers and heme oxygenase-1 in human pulp cells, J. Endod. 32 (1) (2006) 39-43.

[65] F.W. Paula-Silva, A. Ghosh, L.A. Silva, Y.L. Kapila, TNF-alpha promotes an odontoblastic phenotype in dental pulp cells, J. Dent. Res. 88 (4) (2009) 339344.

[66] D.J. Alongi, T. Yamaza, Y. Song, A.F. Fouad, E.E. Romberg, S. Shi, R.S. Tuan, G.T. Huang, Stem/progenitor cells from inflamed human dental pulp retain tissue regeneration potential, Regen. Med. 5 (4) (2010) 617-631.

[67] S.J. Shin, J.I. Lee, S.H. Baek, S.S. Lim, Tissue levels of matrix metalloproteinases in pulps and periapical lesions, J. Endod. 28 (4) (2002) 313-315.

[68] Y.H. Lee, Y.M. Kang, M.J. Heo, G.E. Kim, G. Bhattarai, N.H. Lee, M.K. Yu, H.K. Yi, The survival role of peroxisome proliferator-activated receptor gamma induces odontoblast differentiation against oxidative stress in human dental pulp cells, J. Endod. 39 (2) (2013) 236-241.

[69] D.T. Graves, T. Oates, G.P. Garlet, Review of osteoimmunology and the host response in endodontic and periodontal lesions, J. Oral Microbiol. 3 (2011).

[70] X. Feng, G. Feng, J. Xing, B. Shen, W. Tan, D. Huang, X. Lu, T. Tao, J. Zhang, L. Li, Z. $\mathrm{Gu}$, Repeated lipopolysaccharide stimulation promotes cellular senescence in human dental pulp stem cells (DPSCs), Cell Tissue Res. 356 (2) (2014) 369380.

[71] S. Lee, Q.Z. Zhang, B. Karabucak, A.D. Le, DPSCs from inflamed pulp modulate macrophage function via the TNF-alpha/IDO axis, J. Dent. Res. 95 (11) (2016) 1274-1281.

[72] F.B. Yazid, N. Gnanasegaran, W. Kunasekaran, V. Govindasamy, S. Musa, Comparison of immunodulatory properties of dental pulp stem cells derived from healthy and inflamed teeth, Clin. Oral Investig. 18 (9) (2014) 2103-2112.

[73] G. Guven, C. Altun, O. Gunhan, T. Gurbuz, F. Basak, E. Akbulut, Z.C. Cehreli, Coexpression of cyclooxygenase-2 and vascular endothelial growth factor in inflamed human pulp: an immunohistochemical study, J. Endod. 33 (1) (2007) $18-20$.

[74] C. Yuan, P. Wang, L. Zhu, W.L. Dissanayaka, D.W. Green, E.H. Tong, L. Jin, C. Zhang, Coculture of stem cells from apical papilla and human umbilical vein endothelial cell under hypoxia increases the formation of three-dimensional vessel-like structures in vitro, Tissue Eng. Part A 21 (5-6) (2015) 1163-1172.

[75] M.R. Shin, S.K. Kang, Y.S. Kim, S.Y. Lee, S.C. Hong, E.C. Kim, TNF-alpha and LPS activate angiogenesis via VEGF and SIRT1 signalling in human dental pulp cells, Int. Endod. J. 48 (7) (2015) 705-716.

[76] P. Gentile, V.K. Nandagiri, J. Daly, V. Chiono, C. Mattu, C. Tonda-Turo, G. Ciardelli, Z. Ramtoola, Localised controlled release of simvastatin from porous chitosan-gelatin scaffolds engrafted with simvastatin loaded PLGAmicroparticles for bone tissue engineering application, Mater. Sci. Eng. C Mater. Biol. Appl. 59 (2016) 249-257.

[77] I.C. Tai, Y.C. Fu, C.K. Wang, J.K. Chang, M.L. Ho, Local delivery of controlledrelease simvastatin/PLGA/HAp microspheres enhances bone repair, Int. J. Nanomed. 8 (2013) 3895-3904. 